\title{
Star Wars: Exclusive Superstars and Collusive Outcomes*
}

\author{
Mariano Selvaggi ${ }^{\dagger} \quad$ Luis Vasconcelos ${ }^{\ddagger}$
}

July 2006

\begin{abstract}
We examine the impact of agreements that prohibit "superstars" from switching their services to rivals on firms' ability to collude. Exclusivity (or non-compete) clauses are not uncommon in the sports, entertainment and professional services industries, but courts often refrain from enforcing them owing to inequity and/or restraint of trade considerations. We argue this attitude may be misguided. While in the collusive path exclusion may be inconsequential because firms agree not to hire each other's star, its enforcement level affects the severity of future punishments. For exclusive talent may not be poached by rivals. The ability to sustain tacit collusion may thus be impaired, which in plausible constellations leads to efficiency improvements and more equitable distribution of rents.
\end{abstract}

JEL Classification: J44, K21, L42.

Keywords: collusion, contract enforcement, exclusive contracts, non-compete covenants, supergames, superstars.

\section{Introduction}

Talent is a precious commodity in constant scarce supply. This makes it very expensive. When firms scramble for premium talent in the market (a "star"), they may hold a tight grip on hiring costs by writing exclusivity clauses that prohibit potential stars from dealing with others in the future. That way, the star's outside opportunities plummet. Alternatively firms may sustain tacit understandings whereby they do not try to hire each other's star, thus eschewing "star wars" that consume the rents created by new talent. While both mechanisms are observed in practice, the economics literature contains no formal analysis of the

${ }^{*}$ We would like to thank Ran Abramitzky, Adeline Delavande, David de Meza, Nuno Garoupa, Iliyan Goergiev, José Mata, April Mitchell Franco, Luís Pinto, Guillaume Roger, Johan Stennek, and participants at the 4th Annual International Industrial Organization Conference (Boston) for helpful comments.

${ }^{\dagger}$ Department of Management, Managerial Economics \& Strategy Group, London School of Economics. Tel: +44 (0)20 7955 7544, E-mail: m.selvaggi@lse.ac.uk

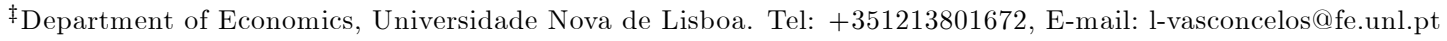


possible linkages between them or the basic trade-offs involved. In this paper we study a setting in which firms repeatedly compete for new talent, and argue that differential enforcement of exclusionary rights over stars affects firms' ability to sustain collusive outcomes. In particular, we show that tighter enforcement of exclusivity may hinder (tacit) collusion because the exclusive-rightholder expects to capture more of the rents created by future stars, which in turn lessens the severity of punishments upon defectors. Hence star wars, where firms engage in fierce competition for free talent, are more likely to occur. This simple reasoning leads to staggering conclusions. Not only may courts that are more prone to enforce exclusivity provisions actually boost the rewards earned by stars, but to the extent that a breakdown of collusion in the market for talent induces pro-competitive behavior in other markets, allocative efficiency and aggregate welfare may also swell. The model permits us to offer a subtle explanation as to why exclusivity flourishes precisely in environments where it receives strong support from enforcement agencies, and to understand why it is frequently the case that only top talent, or "superstars", are restricted by exclusive rights.

Exclusivity occurs when two parties enter into a contractual agreement that prohibits one - or sometimes both - of them from trading with others. While exclusive contracts are often written to govern vertical relationships between firms (e.g. manufacturers and retailers), they are certainly not uncommon in the labour market. One such sort of exclusion occurs when a superbly talented individual, while free to walk away from his or her current job, is contractually forbidden to join other firms in the same industry - one of the employer's rivals. A prominent example of exclusive employment contracts, and one which is indeed very close to the situation delineated in our formal set-up, occurs in sports leagues. ${ }^{1}$ Frequently American football teams and baseball clubs cannot hire players who are "owned" exclusively by competitors unless the player's employer explicitly agrees. In such situations, the exchange of talent in the market typically entails monetary compensations between clubs (i.e. side payments) according to the features of the transfer system. In English football, for instance, clubs and/or managers cannot even discuss transfer conditions with a football player that "belongs" exclusively to another club. In that connection, a recent case is provided by the Arsenal star Ashley Cole, who in 2005 received a fine of $£ 100,000$ by the Premier League following an illegal approach by Chelsea. A Premier League commission found Cole in breach of rule K5, which prohibits a player contracted to a club from approaching another with a view to negotiating a transfer. Chelsea, in turn, was fined $£ 300,000$ for breaking rule K3, which forbids an approach to a player while he is under contract. Other examples along similar lines abound. The NBA, which organizes the professional basketball championship in the US, also applies exclusionary rules regarding the transfer of players between teams. So too do companies in the movies, TV shows and music industries. Very often, young artists sign contracts with record companies embodying exclusive-dealing clauses for several years. ${ }^{2}$

\footnotetext{
${ }^{1}$ Other "celebrities" restricted by exclusivity provisions comprise, among others, movies/TV and music stars, top executives, chatshow and news broadcasters, best-selling authors and, less often, prominent academics/researchers.

${ }^{2}$ Indeed these agreements tend to be rather complete as far as exclusion is concerned. In that connection, it is not unusual
} 
Arguments against and in favour of exclusive contracts abound in the economics literature; yet, to the best of our knowledge, there is no analysis that formally examines the impact of exclusivity provisions on firms' ability to collude in infinitely repeated environments. Let alone models that attempt to draw a link between them in the context of employment contracts and competition for talent. In addition to the heed paid to exclusive contracts in the antitrust arena (see, e.g., Bernheim and Whinston (1998) and Fumagalli and Motta (2005)), the formal literature on exclusivity has been concerned with free-riding problems arising from investment spillovers. For instance, a manufacturer may grant a retailer an exclusive dealership to encourage (efficient) pre-sale services or advertising that would otherwise benefit all retailers carrying the brand - Motta (2004) nicely reviews this reasoning. More recent papers have suggested instead that exclusive trade agreements may be socially beneficial because they affect non-contractible investments that are highly specific to the partnership, thereby alleviating hold-up problems - see Segal and Whinston (2000), De Meza and Selvaggi (2004) and Vasconcelos (2006). However none of these papers tackles the main issue that concerns us here, namely, the potential efficiency and distributional implications of differential enforcement of exclusive contracts when firms can collude in the process of hiring stars. ${ }^{3}$

In what follows, we investigate the impact of exclusive contracts on the extent of collusion that firms that repeatedly compete for a scant resource - talent - can sustain in equilibrium. Particularly we characterise and compare the most profitable collusive equilibria that can be maintained when the courts are more prone to enforce exclusivity clauses. It is well known that owing to statutory reasons, inequity considerations (firms are disproportionately favoured) or antitrust issues, the degree to which courts effectively enforce contractual provisions in general, and exclusivity clauses in particular, varies markedly across jurisdictions (e.g., states in the US or countries). For example the so-called covenants not to compete, or non-compete clauses, also restrain employee mobility and are subject to strong differential enforcement across states in the US (see, e.g., Franco and Mitchell (2005)). ${ }^{4}$ Indeed, more often than not the draconian restrictions originally embedded in these agreements are disregarded by courts. In our model this is encapsulated in a probabilistic enforcement of exclusionary rights. The likelihood that exclusivity is enforced may be subject to different interpretations: perhaps the parties do not know whether the enforcement agency will use a specific performance remedy, or there are conflicting and changing legal attitudes towards exclusionary rights

to specify in the contract that a music label has exclusionary rights over a potential "rock star" not only on earth but also in the outer space.

${ }^{3}$ Segal (2003) does examine the profitability of exclusive and collusive arrangements in a completely different environment of (cooperative) coalitional bargaining. However the link between the degree of enforcement of exclusionary rights and the sustainability of collusive outcomes, which is at the heart of our paper, is not analyzed.

${ }^{4}$ These provisions often pursue the extra objective of insulating firms against competition from employees that walk out carrying with them valuable (e.g. secret, strategically sensitive) information. Employment contracts embedded with a noncompetition clause comprise such professions as scientists, top researchers (see, e.g., the legal battle between Microsoft and Google over Kai-Fu Lee) and top executives, among others. 
(see, e.g., Lafontaine and Slade (2005)), or courts may feel that stipulated damages depart too much from "reasonable" payments, thus dismissing them as inadequate or punitive and refusing to enforce them - see, e.g., Edlin and Reichelstein (1996) and the literature cited there. Relatedly, if the productive interaction between firm and star extends over many periods, one could interpret the probability that exclusivity is enforced as the maximum duration of the exclusivity provision that courts are prepared to enforce. We simply note that any of these interpretations is well-suited to our theoretical framework.

The main thrust of the connection between exclusive rights over stars and collusion in the market for talent is the following. Exclusive employment agreements and coordination between firms that compete for talent are substitute methods of appropriating revenues generated by the stars. In effect both ensure that wage packets remain relatively low. In the presence of collusive behavior in the market for new talent, exclusivity is often immaterial because firms agree not to hire each other's stars. During a punishment phase in which there is increased competition for talent, however, exclusivity is valuable because it prevents rivals from poaching stars. On such occasions, exclusivity is much more instrumental in rent seeking. Hence when courts are more likely to upheld exclusivity clauses, the gains from deviating (the profit from luring the star away from the rival) are large relative to the punishment for deviating (the loss of future profits owing to fierce competition). Ceteris paribus, collusive outcomes are thus harder to maintain.

The remainder of the paper proceeds as follows. In Section 2, we analyze repeated interaction between firms when stars are homogeneous. This enables us to study in a simple setting how the level of enforcement of exclusive contracts between firms and (potential) stars impinges on firms' ability to sustain collusive outcomes. The main result is that if courts are more prone to enforce exclusive contracts, it is harder for firms to cooperate and avoid fierce competition for free talent. Thus stars actually earn higher equilibrium rewards when exclusivity is more likely to be enforced. The underlying intuition has been provided above. We also show that tighter enforcement of exclusive contracts may also be efficiency-enhancing. Based on the concept of multimarket contact pioneered by Bernheim and Whinston (1990), we argue than when firms arguably interact in many markets simultaneously, breaking down collusion in the market for talent may induce competitive behavior in all markets.

In Section 3, we consider a richer model comprising stars and firms with different productivity. This allows us to study how firms' incentives to write exclusive contracts vary across talent, and to examine wealth redistributions across stars as a result of changes in the likelihood of enforcement. With heterogeneity, firms' ability to collude depends on realised talent. Specifically, the more talented a free star is, the harder it is to sustain non-competitive behavior because the temptation to cheat goes up. On such occasions, colluding firms increase the salary packet offered to the star in order to reduce the gains from deviating. Hence uniquely talented stars who are free in the market earn premium wages. Since cooperation never really breaks down, these outcomes are a sort of "cold wars" for talent. Our model also implies that firms find 
exclusivity valuable even along the collusive phase, and that its value is sensitive to the star's talent-in equilibrium, only superstars are bounded by exclusive contracts. Effectively, for less outstanding stars the coordination wage is low even when they are free in the market, so there are no gains from writing exclusive contracts with them.

In this context, increasing the probabilistic enforcement of exclusive contracts has two opposite effects on stars' payoffs. On the one hand, stars lose because they are free less often; on the other hand, when they are free their wages may go up because coordination is harder to sustain - this is a novel effect that this paper emphasizes. The interplay between these two forces ultimately determines whether principals and stars lose or gain from shifts in enforcement level. We show that for stars of exceptional talent the first effect tends to dominate, whereas for stars of moderate talent the second effect is the dominant. Thus, when enforcement increases there is redistribution of surplus from very talented stars to less talented ones. One can also show that principals can be worse off following an increase in exclusivity enforcement. Another implication of our analysis is that exclusive agreements are rampant precisely when courts are more likely to enforce them. While this result seems intuitive, the underlying mechanism at work is subtle. Exclusive contracts are more frequently used not because they are necessarily more effective, but because collusive outcomes are harder to sustain and principals fall back on other ways to appropriate the rents created by their stars.

In Section 4, we make some concluding remarks.

\section{Basic Model}

Consider a market with two identical, infinitely lived principals, $\mathrm{P}_{1}$ and $\mathrm{P}_{2}$. At the beginning of the period, each principal hires an agent from a large pool of homogenous individuals. Agents are embedded with star potential, and those hired in a given period are equally likely to become the single star in the market. ${ }^{5}$ To capture repeated competition between principals for new talent, we assume agents/stars live for only one period. (The pool of agents is replaced every new period.) Thus, talent is constantly in scarce supply. Both principals and agents are risk neutral and maximize expected wealth.

The supergame we study in this paper consists of a discounted, infinitely repeated stage game in which each principal "breeds" the star in the market with probability 0.5. (Throughout we use masculine pronouns for the principals and feminine pronouns for the agents and stars.) Time is discrete (indexed by $\tau$ ) and $\delta$ denotes the common discount factor between stages, with $0<\delta<1$. The precise timing of events within

\footnotetext{
${ }^{5}$ For simplicity, we assume that each period only one of the agents becomes a star. We do not formally model the mechanism by which agents develop into real stars. The important feature in our approach is that only those hired by principals may develop their star potential, which emphasizes the role played by employers in the star-breeding process. Think of principals as football clubs or music labels that spot raw talent, whereas agents could be amateur young players or musicians who need to further their natural talent and to be trained/promoted/groomed to become superstars.
} 
each period - or constituent game - is as follows.

1. Contracting phase. At the outset principals meet agents and make take-it-or-leave-it employment contract offers. (Agents cannot simultaneously work for both principals.) With this assumption we want to capture the idea that there is, ex ante, a competitive supply of potential stars. $\mathrm{P}_{i}$ 's offer takes the form $\phi_{i}=\left(w_{i}, \mu_{i}\right), i \in\{1,2\}$, where $w_{i}$ denotes the agent's binding salary and $\mu_{i} \in\{$ non-exclusive, exclusive $\}$ represents absence or presence of an exclusionary clause that forbids employment with other principals during the period. If $\mathrm{P}_{i}$ 's offer is rejected the matched agent irretrievably returns to the pool of unmatched individuals — she has zero probability of being resampled—whilst the principal draws a new agent, and this process continues until both principals hired their respective agents. ${ }^{6}$ We posit that up-front transfers from agents to principals are infeasible because the former are wealth-constrained and protected by limited liability. ${ }^{7}$

2. Contract enforcement and competition for talent. Once all parties observed the contracts signed in the market, the state of nature is revealed and the identity of the star becomes public knowledge. If the employment contract of the new star includes an exclusionary clause, she may try to get around the exclusivity provision by legally "repudiating" the contract. In that connection, $e \in[0,1]$ stands for the probability that exclusive-dealing arrangements will be enforced by the enforcement agencyi.e. courts of law. ${ }^{8}$ We assume $e$ is exogenous and fixed as it depends, by and large, on the legal environment.

If the star is tied to her principal by an enforceable exclusivity clause, she may stay and earn the contracted wage or quit and get her outside wage (or reservation utility) $w_{0} \geq 0 .{ }^{9}$ If the new star in the market is non-exclusive (either because her employment contract does not embody an exclusivity provision or because courts decided not to enforce it), she is "free talent" and may be poached by other principals. At this point, principals may engage in fierce competition for the free star in the market or tacitly agree not to hire each other's star so as to eschew bidding wars for free talent. It is the ability to collude at this particular stage that lies at the centre of our analysis.

3. Production. At the end of each period production takes place. The star generates (gross) revenues $\pi$ to her employer whereas an ordinary agent generates $w_{0}$, where $\pi>w_{0}$. As stated above, $w_{0}$ also

\footnotetext{
${ }^{6}$ The assumption that principals hold all the bargaining power at the contracting stage simplifies the analysis considerably but is not crucial for our results. This is formally shown in the Appendix.

${ }^{7}$ This implies that two-part tariff offers are also ruled out. We think our assumption is natural and realistic in the context of this paper, since more often than not it is virtually impossible to borrow money in the market against unverifiable talent potential. Yet in Section 2.2 we briefly examine the main implications of relaxing this assumption.

${ }^{8}$ Alternatively but equivalently, think of $e$ as the maximum level of exclusionary rights that courts are able/willing to enforce. In this interpretation $e$ represents the maximum level of exclusivity allowed in this market.

${ }^{9}$ Exclusive stars may not be poached by other employers.
} 
represents the reservation utility/wage or outside opportunity of an ordinary agent. Thus principals are indifferent between remaining inactive in a given period and employing an ordinary agent because in both cases they collect zero. ${ }^{10}$

Throughout we confine ourselves to "collusive" equilibrium outcomes that permit principals to appropriate the revenues created by stars, assuming that in the subgame following a defection there is infinite reversion to the (static) Bertrand-Nash equilibrium of the one-shot game. Our focus on (stationary) trigger strategies entails no loss of generality because, as it will become clear shortly, this strategy profile also characterizes an optimal punishment (see Abreu, 1988). ${ }^{11}$

\subsection{Exclusivity Enforcement and Collusion}

This section discusses the key forces at work in our analysis within a simplified setting of repeated interaction between firms in the market for new talent. Concretely, we illustrate how the (probabilistic) level of enforcement of exclusive employment contracts affects the critical discount factor above which firms can sustain collusive outcomes.

One-Shot Game. We begin by examining the (static) equilibrium of the one-shot game. Since in this milieu collusion is unfeasible, its associated payoffs represent what principals expect to collect in each period of the punishment phase. Without loss of generality, suppose $\mathrm{P}_{1}$ 's agent is the new star in the market. Suppose also that the contract between $\mathrm{P}_{1}$ and his agent is $\phi_{1}=\left(w_{1}\right.$, exclusive $)$, where $w_{0} \leq w_{1}<\pi .{ }^{12}$ If exclusivity is enforced, the principals' payoffs are given by

$$
\begin{aligned}
\sigma_{1}^{E} & =\pi-w_{1}, \\
\sigma_{2}^{E} & =0 .
\end{aligned}
$$

When the exclusivity deal is enforced, the star's equilibrium reward equals $w_{1}$. Since the other principal can be excluded, the contract with the star simply needs to guarantee she can make at least her outside option from quitting. ${ }^{13}$ Hence $\mathrm{P}_{1}$ keeps the star and reaps $\pi-w_{1}$ whereas $\mathrm{P}_{2}$ employs an ordinary agent

\footnotetext{
${ }^{10}$ We denote by $w_{0}$ the revenue generated by an ordinary agent to simplify notation. Throughout most of the paper, we assume that owing to convention or legal restrictions the agent may not be paid less than $w_{0}$. So think of $w_{0}$ as a legally enforceable minimum wage.

${ }^{11}$ Trigger strategies, or Nash reversions, refer to strategies that punish deviations from the (tacit) collusive outcome by reverting to the one-shot Nash equilibrium forever. Thus, they are subgame perfect and entail an eternal punishment phase: it lasts for all remaining periods of the game.

${ }^{12}$ It is also without loss of generality to consider a contracted wage $w<\pi$, since $\pi$ is the maximum payoff (gross of wage payments) that a principal can obtain.

${ }^{13}$ This is a simplifying assumption. In the Appendix A.2 we show that the main conclusion of this section also obtains when the star has some bargaining power and can induce a wage renegotiation ex post.
} 
and collects zero. This outcome must be compared with the alternative situation in which the star is "free talent" in the market. On such occasions, we posit that principals scramble for the new talent by making simultaneous wage offers to the star. As is well known, in the unique solution of this Bertrand-type (auction) game principals bid away all the revenues created by the star. ${ }^{14}$ As a result, the star's equilibrium reward equals $\pi$ and the principals' payoffs come down to

$$
\sigma_{1}=\sigma_{2}=0
$$

Expressions (2.1) and (2.3) imply that principals will optimally write exclusivity deals during the punishment phase. (This holds, of course, so long as the cost of writing exclusive contracts is not "too large".) Since the principals' payoff are decreasing in $w_{i}$, the equilibrium of the constituent game has $\phi_{i}=\left(w_{0}\right.$, exclusive $)$ for $i \in\{1,2\}$. Therefore the principals' expected payoffs when, say, $\mathrm{P}_{1}$ 's agent becomes the star are as follows:

$$
\begin{aligned}
& \sigma_{1}^{N C}=e\left(\pi-w_{0}\right), \\
& \sigma_{2}^{N C}=0 .
\end{aligned}
$$

Effectively, when exclusivity is enforced by courts $\mathrm{P}_{1}$ and $\mathrm{P}_{2}$ collect $\pi-w_{0}$ and zero, respectively, whereas the star gets $w_{0}$. This case occurs with probability $e$. In the presence of free talent, however, principals compete fiercely and the star goes to whoever pays the highest wage. As a result, the star's equilibrium reward escalates to $\pi$ and both principals get zero. This case occurs with the complementary probability $1-e$. So long as $e>0$ and the cost of writing exclusivity deals is relatively low (e.g., negligible transaction costs), principals always sign exclusive contracts with their agents in the punishment phase and expect to reap positive gains.

Infinitely Repeated Game. We now consider the supergame in which principals tacitly agree not to compete for the new star in the market. To be more precise, collusive behavior by principals means that $\mathrm{P}_{i}$ abstains from making a (secret and binding) wage offer to a star who was initially hired by $\mathrm{P}_{-i}$. In this way principals avert bidding away the rents created by free talent. Importantly, we posit that no side payments between principals are allowed owing to antitrust legislation. So irrespective of whether the star is exclusive or not, with coordination $\pi$ is always captured by the principal who initially contracted with the star.

A non-competitive (or cooperative) equilibrium outcome may be characterized as a path of contract offers and associated payoffs $\left\{\phi_{i}(\tau), \sigma_{i}^{C}(\tau)\right\}_{\tau=0}^{\infty}, i=\{1,2\}$, where it is understood that deviations from this path are punished by retreating to the static solution forever. ${ }^{15}$ Since this equilibrium entails an implicit

\footnotetext{
${ }^{14}$ The wage offers made by principals to the star might be secret.

${ }^{15}$ To be fully rigorous, this characterization of a non-competitive equilibrium outcome should also include the principals' wage offers to a free star in the market. Since these offers are not made along a collusive equilibrium path, we omit this variable to reduce notational burden.
} 
understanding proscribing principals from hiring each other's stars, the most profitable outcome exhibits contracted wages equal to $w_{0} \cdot{ }^{16}$ The payoff stream from the collusive path is thus given by

$$
\frac{\delta}{1-\delta} \frac{1}{2}\left(\pi-w_{0}\right)
$$

In effect principals split 50:50 the benefits from collusion because both are equally likely to groom agents for star. Notice that exclusivity is in fact immaterial for principals' payoffs when collusive outcomes are sustainable. Hence exclusivity and collusion are to some extent substitute methods of appropriating the rents created by new stars. As we shall see, however, the probability of enforcement of exclusive contracts, $e$, impinges on principals' ability to maintain non-competitive behavior.

To investigate the linkage between exclusivity and collusive outcomes, suppose $\mathrm{P}_{-i}$ deviates from the tacit agreement by (secretly) offering $w_{0}+\varepsilon$ to $\mathrm{P}_{i}$ 's star when she is free, for an arbitrarily small $\varepsilon$. Since the star accepts $\mathrm{P}_{i}$ 's binding offer, the most a principal can gain from cheating on the collusive arrangement is

$$
\pi-w_{0}
$$

Principals anticipate that any deviation from the (equilibrium) collusive path at time $x$ will be punished by a reversion to the Bertrand-type (static) solution forever, i.e., from $x+1$ on. Therefore if the expected value of such punishments are large enough to outweigh the immediate gains from cheating, the collusive outcome is sustainable. From (2.4) through (2.6), the expected discounted loss of future profits equals

$$
\frac{\delta}{1-\delta} \frac{1}{2}(1-e)\left(\pi-w_{0}\right)
$$

(2.8) is positive and decreasing in $e$. While heightened contract enforcement leaves the payoff stream from collusive behavior unaffected, it does increase principals' expected payoffs in the punishment path. When courts are more prone to enforce exclusivity provisions the punishment for deviating softens because principals are more likely to be insulated from competition and reap the rents created by their exclusive stars. For $e$ large enough, the reward for cheating on the agreement may therefore outweigh the cost. (Perfect enforceability provides the lowest punishment, i.e. zero punishment, because the star is tied to the principal till the end of the period.) The fact that the expected losses associated with the punishment phase are decreasing in probability with which courts enforce exclusionary rights over stars plays a major role in our analysis.

A collusive outcome is sustainable if and only if $\mathrm{P}_{i}$ 's short-term gains from deviating are compensated by the subsequent long-term losses, i.e., whenever [use (2.7) and (2.8)]:

$$
\pi-w_{0} \leq\left(\frac{\delta}{1-\delta}\right) \frac{1}{2}(1-e)\left(\pi-w_{0}\right)
$$

\footnotetext{
${ }^{16}$ In this simple model with homogeneous stars, one can show that if collusion is not sustainable with contracted wages $w_{0}$ then it is not sustainable with any other contracted wages higher than $w_{0}$.
} 
which is equivalent to

$$
e \leq \frac{3 \delta-2}{\delta}=e^{*}
$$

Expression (2.10) can alternatively be written as $\delta \geq \underline{\delta}$, where $\underline{\delta}=2 /(3-e)$ is the critical discount factor below which principals are unable to sustain tacit collusion in a repeated-interaction environment. This is depicted in Figure 1. Since $\partial \underline{\delta} / \partial e>0$, the sustainability of collusive behavior in the market for new stars decreases with $e$. More particularly, for $\delta<2 / 3$ principals cannot sustain collusive subgame-perfect equilibria irrespective of the value of $e$. On such occasions the level of enforcement of exclusive contracts plays no role whatsoever. For $\delta \geq 2 / 3$, however, principals can sustain collusion if and only if $e$ is relatively small (i.e., $e$ must satisfy 2.10). In consequence, when exclusive employment contracts are more likely to be enforced by courts there exist fewer discount factors for which collusion between principals is sustainable - the set of subgame-perfect equilibria that yield collusion is reduced. Differently put, the ability of principals to sustain collusive outcomes is impaired by heightened enforcement of exclusivity clauses. This idea is summarized in the following proposition.

Proposition 1 If $\delta \in\left[0, \frac{2}{3}\right)$, a collusive outcome cannot be sustained irrespective of the value of $e$. If $\delta \in\left[\frac{2}{3}, 1\right]$, however, a collusive outcome can be sustained iff the probability of enforcement satisfies the condition $e \leq \frac{3 \delta-2}{\delta}$.

The above result has intriguing distributional implications. To see this, suppose that $\delta \in\left[\frac{2}{3}, 1\right)$. Then, whenever an increase in $e$ upsets the implicit understanding between principals it also boosts the equilibrium rewards earned by stars. This is because after switching to the non-collusive equilibrium path stars earn competitive salaries whenever they are free, while in the collusive path star always get their reservation utility $w_{0}$. We deal with distributional effects more thoroughly in Section 3, where some stars might earn wages above $w_{0}$ even along the equilibrium collusive path.

It is easy to see that in the presence of costless contracting, colluding principals lose nothing by always writing exclusive clauses with their agents. However, in the presence of positive but negligible transaction costs colluding principals would never write exclusive contracts. Clearly this bang-bang prediction is not very realistic. We shall come back to this issue in Section 5, where an enriched version of our basic model does permit us to study when and why costly exclusive employment contracts are signed.

\subsection{Welfare Implications}

Above we argued that the degree of enforcement of exclusive employment contracts (or non-compete clauses) may affect principals' ability to sustain non-competitive behavior in the "market for new talent". Yet the 


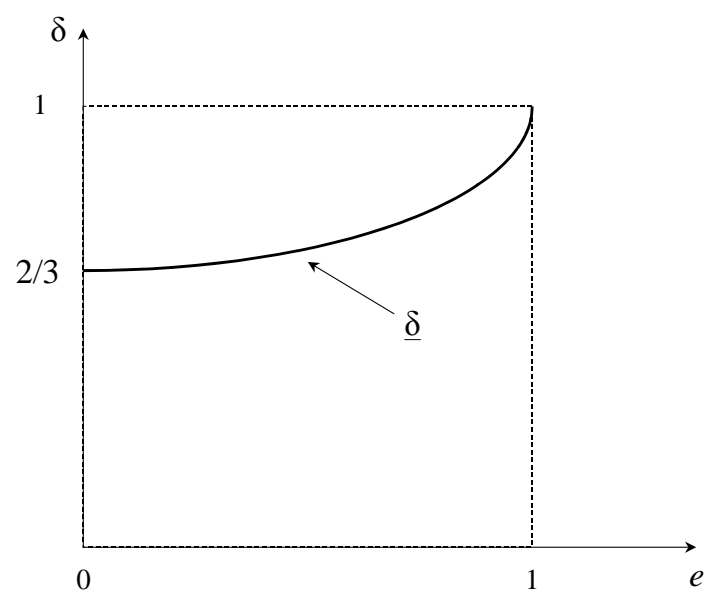

Figure 1: Relationship between $e$ and critical discount factor.

mechanism highlighted there was neutral in terms of aggregate welfare because principals merely collude in order to maintain stars' rewards relatively low. In such a context, increases in $e$ may only induce distributional shifts. This need not always be the case though. In this subsection we extend the basic framework by introducing other markets, and show that our framework entails efficiency implications whenever less collusive behavior in the market for talent leads to pro-competitive conduct in other, not necessarily linked, markets in which principals operate. On such occasions, tighter enforcement of exclusivity deals with potential stars enhances allocative efficiency and benefits society as a whole. The analytical vehicle we rely upon for doing this exercise is the concept of multimarket contact pioneered by Bernheim and Whinston (1990).

The main result is simple. When principals cannot maintain collusive outcomes in other markets in which they participate unless they simultaneously sustain non-competitive behavior in the market for new talent, breaking down collusion in the latter market automatically induces competitive behavior in all markets. If the shift of regime in turn raises social welfare in any of those other markets (maybe because joint monopoly pricing can no longer be sustained in a subgame-perfect equilibrium), then stricter enforcement of exclusive employment agreements turns out to be efficiency-enhancing.

To formalize this intuition, suppose principals $\mathrm{P}_{1}$ and $\mathrm{P}_{2}$ operate (i.e. interact) in two separate markets, $A$ and B. Following Bernheim and Whinston (1990), we assume the markets are technologically independent. The interaction between principals occurs at the same set of points in discrete time, $\{\tau\}_{\tau=0}^{\infty} . \mathrm{P}_{i}$ 's static payoff function in market $j$ is denoted by $\sigma_{i j}\left(s_{i j}, s_{-i j}\right)$, where $s_{i j}$ is the strategy chosen by $\mathrm{P}_{i}$ in market 
$j .{ }^{17}$ To keep things simple, assume the punishment phase in market $j$ yields the same discounted payoff $\psi_{j}$ to both principals in the next period, and restrict attention to stationary equilibrium paths. As shown in the previous section, generally $\psi_{A}(e)$ will be increasing in the level of contract enforcement $e$ (see 2.8). So we just posit that $\partial \psi_{A}(e) / \partial e>0$.

When principals treat the two markets in isolation, strategies $\left(s_{1 j}, s_{2 j}\right)$ constitute a perfect equilibrium outcome path in market $j$ if and only if

$$
\sigma_{i j}\left(\hat{s}_{i j}\left(s_{-i j}\right), s_{-i j}\right)+\delta \psi_{j} \leq\left(\frac{1}{1-\delta}\right) \sigma_{i j}\left(s_{i j}, s_{-i j}\right)
$$

for $i \in\{1,2\}$, where $\hat{s}_{i j}\left(s_{-i j}\right)$ is $\mathrm{P}_{i}$ 's static best response to $s_{-i j}$ (see Bernheim and Whinston (1990)). This is the analogue of condition (2.9). Next, suppose that (2.11) holds strictly for $j=A$ but does not hold for $j=B$, namely

$$
\sigma_{i A}\left(\hat{s}_{i A}\left(s_{-i A}\right), s_{-i A}\right)+\delta \psi_{A}(e)<\left(\frac{1}{1-\delta}\right) \sigma_{i A}\left(s_{i A}, s_{-i A}\right)
$$

and

$$
\sigma_{i B}\left(\hat{s}_{i B}\left(s_{-i B}\right), s_{-i B}\right)+\delta \psi_{B}>\left(\frac{1}{1-\delta}\right) \sigma_{i B}\left(s_{i B}, s_{-i B}\right) .
$$

These inequalities imply that if principals treat the two markets unconnectedly, collusive strategies $\left(s_{1 j}, s_{2 j}\right)$ are supportable as a subgame-perfect equilibrium in market $A$ (the market for new talent) but not in market $B$. As it turns out, principals could do better by "pooling" the incentive constraints in order to sustain collusive outcomes in the two markets. Recognizing their multimarket contact, they could agree that any deviation in either market will be met with future punishments in both markets. ${ }^{18}$ In this context, strategies $\left[\left(s_{1 A}, s_{2 A}\right),\left(s_{1 B}, s_{2 B}\right)\right]$ are supportable as a perfect equilibrium (collusive) outcome if

$$
\sum_{j=A, B}\left[\sigma_{i j}\left(\hat{s}_{i j}\left(s_{-i j}\right), s_{-i j}\right)+\delta \psi_{j}\right] \leq\left(\frac{1}{1-\delta}\right) \sum_{j=A, B} \sigma_{i j}\left(s_{i j}, s_{-i j}\right) .
$$

As noted by Bernheim and Whinston (1990), this pooling device may be a method of relaxing binding constraints so as to increase principals' expected profits. In the case being considered here, non-competitive behavior in market $A$ is essential to sustain collusive outcomes in market $B$ because only the former constraint was assumed to be slack. Differently put, principals can use their slack enforcement power in the market for new talent to overcome incentive problems in market $B$. Our point is that higher enforceability of exclusive employment agreements might in fact break down collusion in "both" markets. To see this suppose, for example, there exists $\bar{e}$ such that

$$
\sigma_{i A}\left(\hat{s}_{i A}\left(s_{-i A}\right), s_{-i A}\right)+\delta \psi_{A}(\bar{e})=\left(\frac{1}{1-\delta}\right) \sigma_{i A}\left(s_{i A}, s_{-i A}\right)
$$

\footnotetext{
${ }^{17}$ Following Bernheim and Whinston (1990), strategy $s_{i B}, i \in\{1,2\}$, could be interpreted as the price announced by $\mathrm{P}_{i}$ in market $B$. If we also assumed that demand in market $B$ is a decreasing continuous function of the final price and that aggregate profits are concave in price, welfare implications would easily obtain.

${ }^{18}$ Since any deviation triggers a punishment phase, a principal would optimally deviate in both markets.
} 
and

$$
\sigma_{i B}\left(\hat{s}_{i B}\left(s_{-i B}\right), s_{-i B}\right)+\delta \psi_{B}>\left(\frac{1}{1-\delta}\right) \sigma_{i B}\left(s_{i B}, s_{-i B}\right) .
$$

In these circumstances, (2.12) fails to hold for any $e \geq \bar{e}$. Our comparative statics thus indicate that when $e$ increases, firms' ability to punish in market $A$ decreases. The novelty here is that the sustainability of more global collusive arrangements involving other markets may also collapse. Hence, when $e$ rises aggregate welfare goes up whenever the breakdown of collusion in those other markets has positive welfare implications.

\subsection{Monetary Transfers at the Contracting Stage}

The above analysis rests on the assumption that agents are unable to make up-front payments to principals because they are liquidity constrained. While this is an appropriate assumption if, for example, agents lack initial wealth and cannot borrow against (potential) talent, it evidently poses a rent-extraction problem for principals. This is because in the absence of collusion, non-exclusive stars reap some of the rents created in the market. In effect principals provide agents with a chance to become valuable merchandise but are unable to "charge" for this service at the outset. When monetary transfers from agents to principals at the contracting stage are possible, principals can appropriate more of the expected surplus created in the market through a suitable (signing-up) fee paid up front. That way rent-extraction problems disappear.

Under these conditions, collusion becomes unattainable independently of the probability of enforcement $e$. Indeed, in all likelihood principals will not be bothered about writing exclusive contracts with their potential stars. This is because a principal can reap in expected terms exactly the same rents with an up-front entry fee as with an exclusive employment contract. As a result, the gains from collusive behavior evaporate and exclusivity does not impinge on the principals' inability to sustain collusion.

This "irrelevance" result is formally summarized in the following proposition.

Proposition 2 If $A$ can pay $P_{i}$ an up-front monetary transfer at the contracting stage, then the probability of enforcement e does not affect sustainability of collusion. Further, in this case collusion does not boost the principals' equilibrium payoffs.

\subsection{Asymmetric Star-Breeding Technologies}

In this section we briefly consider the case in which principals have distinct probabilities of breeding superstars. Perhaps the available resources to spend searching and forming potential stars vary across principals, with the result that one of them creates celebrities more frequently than the other. Be that as it may, we posit that $\mathrm{P}_{i}$ breeds the star with probability $\rho_{i}$ whereas $\mathrm{P}_{-i}$ does it with probability $1-\rho_{i}$, where $\rho_{i} \in[0,1]$.

The chief difference between this scenario and the symmetric one considered above is given by the principal's discounted payoffs under collusion and non-collusion. Here the present value of $\mathrm{P}_{i}$ 's expected 
payoff when principals can sustain tacit collusion is

$$
\frac{\delta}{1-\delta} \rho_{i}\left(\pi-w_{0}\right)
$$

After any defection, the discounted payoff to $P_{i}$ is in turn given by

$$
\frac{\delta}{1-\delta} \rho_{i} e\left(\pi-w_{0}\right)
$$

In consequence, the principals' loss as a result of deviation from a collusive behavior amounts to

$$
\frac{\delta}{1-\delta} \rho_{i}(1-e)\left(\pi-w_{0}\right)
$$

Since the gains from cheating when the star is free talent in the market are again captured by (2.8), principals can sustain collusion as a subgame-perfect equilibrium if and only if

$$
\pi-w_{0} \leq \frac{\delta}{1-\delta}(1-e)\left(\pi-w_{0}\right) \times \min \left\{\rho_{i},\left(1-\rho_{i}\right)\right\} .
$$

This expression confirms our previous conclusion that as $e$ rises, non-competitive behavior in the market for stars is more difficult to sustain. Further, very asymmetric principals also find it relatively more difficult to sustain collusive equilibria because the term $\min \left\{\rho_{i}, 1-\rho_{i}\right\}$ becomes smaller - the enforcement level $e$ for which collusion is sustainable is lower. Formally;

Proposition 3 When the asymmetry between principals' star-breeding technologies increases, collusive agreements are more difficult to sustain. Specifically, the minimum enforcement level below which collusion can be sustained as a SPE decreases with $\left|\rho_{i}-\frac{1}{2}\right|$.

This conclusion is in line with prior literature on tacit collusion: more asymmetry between firms makes implicit collusion less sustainable. The underlying rationale for our result is somewhat different though. Effectively, in most of the existing literature the mechanism at work is that a larger firm has more to gain from a deviation and cannot be punished so severely by the smaller ones. Hence more asymmetry is procompetitive because the dominant firm's incentive to defect on the agreement swells [see, e.g., Compte et al. (2002)]. Here, however, it is the weakest principal who finds defection relatively more attractive. As this principal faces a dismal prospect of breeding its own stars in the future, the immediate gains from a defection in the current period outweigh the longer-term losses. A related result arises in the Industrial Organization literature. With different unit costs and no side payments, joint profit maximization might entail zero production by the less efficient firm which is thus better off deviating [see, e.g., Feuerstein (2005)]. Again, more asymmetry restricts the ability of firms to tacitly collude. 


\section{Heterogeneous Principals and Stars}

In this section we consider a richer setting in which stars embody a quality index. This permits us to take a first step towards explaining why principals write costly exclusive employment contracts even when they can sustain collusion in the hiring process.

Concretely, the star's innate talent or productivity is captured by the random variable $\tilde{\theta} \in[\underline{\theta}, \bar{\theta}], 0<\underline{\theta}<\bar{\theta}$, with continuous distribution function $F($.) (density $f($.$) ) on its support. Each period, \theta$ denotes the realized state of nature. For now, we shall assume that $\theta$ is observed by all parties together with the identity of the new star - one case of asymmetric information is considered in Section 3.2.

$\pi_{i}(\theta), i \in\{1,2\}$, represents the (gross) revenue created by a $\theta$-type star who works for $\mathrm{P}_{i}$. Hence principals may value talent differently. We posit that $\pi_{i}(\theta)$ is increasing and continuous, and that $\pi_{i}(\underline{\theta})>w_{0}$ for $i=\{1,2\}$. As in previous sections, the principal who hires a standard agent collects zero. Hence "agent" can formally be treated as an individual for whom $\theta=0$, with the associated payoff to the principal $\pi_{i}(0)=w_{0}$.

We allow for transfers of talent between principals that lead to ex post efficiency. So, if the star is allocated to a low-value principal after the "contract enforcement and competition for talent" stage (either because the principal is the recepient of exclusivity or because he "won" the star at the competition stage), principals may implement side payments so as to exchange the star and achieve a mutually beneficial outcome. It is assumed that a fixed, exogenously given share $\lambda_{i}$ of the surplus from Pareto-improving transfers goes to $\mathrm{P}_{i} \cdot{ }^{19}$

As in previous sections, we start the analysis of sustainable collusive outcomes by examining the static equilibrium of the one-shot game. ${ }^{20}$ Suppose first that $\mathrm{P}_{i}$ holds exclusive rights over the star in realization

\footnotetext{
${ }^{19}$ Implicit in our analysis is the supposition that only principals collect shares of the renegotiation surplus. Our results do not hinge on this stark assumption, though, and the effect on the analysis of relaxing this simplicity of bilateral bargaining is discussed in the Appendix.

${ }^{20}$ As in Section 2, principals use their privileged position at the contracting stage. So they will both make the most profitable wage offers and sign non-compete agreements (i.e. exclusive contracts) with their agents. Therefore, equilibrium contracts in the one-shot game (and consequently along the punishment phase) are given by $\phi_{i}=\left(w_{0}\right.$, exclusive $), i \in\{1,2\}$. The exclusive contracts that we consider can be interpreted as contracts whose fee to break the exclusivity clause is infinite. So, it is never optimal to a principal to break that clause and hire a star that is exclusive to the other principal. In the spirit of Aghion and Bolton (1987), we could consider contracts that explicitly specify the (finite) fee associated with a break of the exclusivity clause. In principle, such fee could be used by a contracting principal to extract surplus from a principal with superior valuation for the star. However, in a model like ours in which principals always renegotiate inefficient outcomes, an exclusive contract specifying a finite penalty fee is never superior (in terms of surplus extraction) to an exclusive contract with an infinite fee. This is because, a principal with the highest star valuation facing a star tied to the other principal by an exclusive contract specifying a fee that he considers excessively high, can always reject to pay the fee and consequently not hire the star. By doing so, he forces the other principal into renegotiation, in which case he obtains the same as if the star's exclusive contract had an infinite fee.
} 
$\theta$. In this case, principals' payoffs are given by

$$
\sigma_{i}^{E}(\theta)=\pi_{i}(\theta)-w_{0}+\lambda_{i}\left[\max \left\{\pi_{i}(\theta), \pi_{-i}(\theta)\right\}-\pi_{i}(\theta)\right]
$$

and

$$
\sigma_{-i}^{E}(\theta)=\lambda_{-i}\left[\max \left\{\pi_{i}(\theta), \pi_{-i}(\theta)\right\}-\pi_{i}(\theta)\right]
$$

where superscript " $E$ " means enforceable exclusivity. The logic behind (3.1)-(3.2) is as follows. $\mathrm{P}_{i}$ and $\mathrm{P}_{-i}$ collect their default-option payoffs, $\pi_{i}(\theta)-w_{0}$ and 0 respectively, plus a fraction of any surplus from renegotiation. For $\mathrm{P}_{-i}$ is contractually prevented from poaching $\mathrm{P}_{i}$ 's star. Underlying the difference between (2.1)-(2.2) and (3.1)-(3.2) is the supposition that the principal who holds exclusive rights over new talent may agree to transfer the star to its (superior) competitor whenever this action is efficiency-enhancing.

Suppose now that $\mathrm{P}_{i}$ 's star is free in the market. The maximum wage $\mathrm{P}_{i}$ is willing to pay to the star in realization $\theta, w_{i}(\theta)$, leaves the principal indifferent between wining and losing the star to his rival. Hence $w_{i}(\theta)$ must satisfy the following condition:

$$
\pi_{i}(\theta)-w_{i}(\theta)+\lambda_{i}\left[\max \left\{\pi_{i}(\theta), \pi_{-i}(\theta)\right\}-\pi_{i}(\theta)\right]=\lambda_{i}\left[\max \left\{\pi_{i}(\theta), \pi_{-i}(\theta)\right\}-\pi_{-i}(\theta)\right]
$$

Effectively when $\mathrm{P}_{i}$ hires the star he gets $\pi_{i}(\theta)-w_{i}(\theta)$ plus a fraction of the renegotiation surplus, if any. When $\mathrm{P}_{i}$ loses the star to his rival, he gets a positive payoff only when $\pi_{i}(\theta)>\pi_{-i}(\theta)$. Expression (3.3) implies that $w_{i}(\theta)=\pi_{i}(\theta)+\lambda_{i}\left[\pi_{-i}(\theta)-\pi_{i}(\theta)\right]$. Since $\lambda_{i}+\lambda_{-i}=1$, it follows that $w_{i}(\theta)=w_{-i}(\theta)$, i.e., the maximum rewards that $\mathrm{P}_{i}$ and $\mathrm{P}_{-i}$ are willing to offer to the free star are identical. Therefore, in the absence of collusion there is a unique equilibrium of the bidding game in which both principals' offer the maximum wage and their payoffs are given by the r.h.s. of (3.3). Namely; ${ }^{21}$

$$
\sigma_{i}^{N C}(\theta)=\lambda_{i}\left[\max \left\{\pi_{i}(\theta), \pi_{-i}(\theta)\right\}-\pi_{-i}(\theta)\right], \text { for } i=1,2 \text {. }
$$

We denote by $w^{N C}(\theta)$ the equilibrium non-collusive wage of a free star of quality $\theta$, where $w^{N C}(\theta)=$ $\lambda_{1} \pi_{2}(\theta)+\lambda_{2} \pi_{1}(\theta)$ is increasing in $\theta .^{22}$ By looking at (3.4), we can infer that the payoff to the highestvalue principal is strictly positive only when he has some bargaining power. So a principal who not only has relatively high bargaining power but is much more productive than his competitor will manage to appropriate most of the surplus created by free stars in the market.

\footnotetext{
${ }^{21}$ Notice that if $\lambda_{i}=1$ if $\pi_{i} \geq \pi_{-i}$ and $\lambda_{i}=0$ otherwise, we obtain a standard Bertrand-type equilibrium outcome in which the winning principal pays a salary equal to the value of the other principal.

${ }^{22}$ The star's highest salary thus occurs when the principals are identical or the most efficient one has no bargaining power. The star's lowest salary occurs when the bargaining power of the most efficient principal equals one-her reward is given by the other principal's valuation. Finally, when $\lambda_{i}=\lambda_{-i}=0.5$ the star's reward locates halfway between the values of the two principals.
} 
To sum up, $\mathrm{P}_{i}$ 's expected payoff in the (static) equilibrium of the one-shot game is given by

$$
\lambda_{i}\left[\max \left\{\pi_{i}(\theta), \pi_{-i}(\theta)\right\}-\pi_{-i}(\theta)\right]+e\left[\pi_{i}(\theta)-w_{0}\right] .
$$

Thus the discounted payoff stream from the punishment path amounts to

$$
\frac{\delta}{1-\delta} E_{\theta}\left\{\lambda_{i}\left[\max \left\{\pi_{i}(\theta), \pi_{-i}(\theta)\right\}-\pi_{-i}(\theta)\right]+\frac{1}{2} e\left[w^{N C}(\theta)-w_{0}\right]\right\} .
$$

Principals always capture their respective shares of the surplus from renegotiation. In addition, a principal expects to appropriate the difference between the non-collusive wage and the reservation wage whenever he breeds an exclusive star (which occurs with probability $e / 2$ ).

Next, let us compute the expected discounted value of principals' profits along a collusive path. To this end, we extend the notion of collusion to encompass situations in which principals tacitly agree on an upper bound to the salaries offered to free stars. More specifically, a collusive agreement is defined by a schedule $w^{C}(\cdot)$ that specifies the maximum wage $w^{C}(\theta)$ that principals can offer to a $\theta$-type free star. Throughout the following analysis, we refer to this wage as the cooperation wage and to $w^{C}(\cdot)$ as the cooperation wage schedule. A deviation from an agreement with cooperation wage schedule $w^{C}(\cdot)$ occurs whenever a principal offers a wage bigger than $w^{C}(\theta)$ to a $\theta$-type star that is free. ${ }^{23}$ We thus allow for on-equilibrium realizations in which $w^{C}(\theta)>w_{0}$. This is a generalization of the type of collusive agreement studied in Section 2 because it enables principals to sustain (some) wage cooperation when coordination on the lowest possible wage, $w_{0}$, is not sustainable. ${ }^{24}$ Finally, note that in a collusive equilibrium path in which principals tacitly coordinate on wage schedule $w^{C}(\cdot)$, equilibrium bids for a $\theta$-type free star equal $w^{C}(\theta) \geq w_{0}$ - the wage prescribed by $w^{C}(\cdot)$. (We assume that whenever a star receives identical offers from both principals, she accepts the one made by her current employer.)

When $\mathrm{P}_{i}$ 's agent becomes a $\theta$-type free star and principals cooperate on the wage schedule $w^{C}(\cdot)$, their equilibrium payoffs are given by

$$
\begin{aligned}
\sigma_{i}^{C}(\theta) & =\pi_{i}(\theta)-w^{C}(\theta)+\lambda_{i}\left[\max \left\{\pi_{i}(\theta), \pi_{-i}(\theta)\right\}-\pi_{i}(\theta)\right], \\
\sigma_{-i}^{C}(\theta) & =\lambda_{-i}\left[\max \left\{\pi_{i}(\theta), \pi_{-i}(\theta)\right\}-\pi_{i}(\theta)\right] .
\end{aligned}
$$

\footnotetext{
${ }^{23}$ A similar form of collusive agreement is used in Rotemberg and Saloner (1986).

${ }^{24}$ Note that this type of collusion comprises, as special cases, situations in which principals never try to hire each other's stars and fully competitive outcomes. The former occur when coordination focuses on the wage schedule $w^{C}(\theta)=w_{0}$ for all $\theta \in[\underline{\theta}, \bar{\theta}]$, whereas the latter occur when $w^{C}(\theta)=w^{N C}(\theta)$ for all $\theta \in[\underline{\theta}, \bar{\theta}]$.

We did not consider explicitly this more general form of collusion in Section 2. We considered only collusive outcomes with cooperation wage $w_{0}$. This was without loss of generality because with homogeneous stars, a collusive outcome with cooperation wage $w^{C} \geq w_{0}$ is sustainable if and only if it is with cooperation wage $w_{0}$. Further, by focusing on equilibria with cooperation wage $w_{0}$ we focused on the most profitable equilibria to principals. As we shall see, this is not the case when stars are heterogeneous in terms of talent.
} 
Hence $\mathrm{P}_{-i}$ gets exactly what it would have obtained had principals abstained from colluding (compare (3.4) with (3.7)). $\mathrm{P}_{i}$ gets, in addition to that, the difference between the star's competitive wage and the collusion wage, i.e., $\sigma_{i}^{C}(\theta)=\sigma_{i}^{N C}(\theta)+\left[w^{N C}(\theta)-w^{C}(\theta)\right]$.

When $\mathrm{P}_{i}$ 's star is exclusive, however, the principals' ability to collude is irrelevant and their payoffs are given by $\sigma_{i}^{E}(\theta)$ [as given by (3.1)-(3.2)], $i \in\{1,2\}$, so long as $\mathrm{P}_{i}{ }^{\prime}$ initial contract with the star specifies wage $w_{0}$.

Unlike in Section 2, enforcement of exclusive contracts is important even along the collusive path. For in any equilibrium outcome with cooperation wage $w^{C}(\theta)>w_{0}$, principals are better off when exclusivity is enforced because on such occasions the recipient of exclusivity also appropriates $w^{C}(\theta)-w_{0}$. Thus, as long as $e>0$, principals are better off signing exclusive employment agreements with their agents (despite non-negligible transaction costs). In the analysis that follows we shall focus on the most profitable collusive equilibrium to principals. We thus focus on collusive equilibria in which principals sign (on-the-equilibrium path) the most favorable contract to them, i.e., equilibria in which $\phi_{i}=\left(w_{0}\right.$, exclusive $), i \in\{1,2\}$.

The above analysis implies that the principals' (symmetric) expected discounted payoffs when they can sustain collusion in a subgame-perfect equilibrium path equal

$$
\frac{\delta}{1-\delta} E_{\theta}\left\{\lambda_{i}\left[\max \left\{\pi_{i}(\theta), \pi_{-i}(\theta)\right\}-\pi_{-i}(\theta)\right]+\frac{1}{2}\left[w^{N C}(\theta)-w^{C}(\theta)\right]+\frac{1}{2} e\left[w^{C}(\theta)-w_{0}\right]\right\} .
$$

The intuition is as follows. A principal expects to always collect the first term in the curly brackets of (3.8) irrespective of whether he initially contracted with the star or not. The second term represents the additional expected payoff that accrues to a colluding principal when its agent becomes a star, whereas the third term captures the extra payoff to a colluding principal that employs an exclusive star. Notice that in terms of expected aggregate payoffs to principals, collusion is equivalent to enforceable exclusivity only if the cooperation wage equals $w_{0}$.

Consider now the net gains from cheating on the collusive agreement. Particularly, suppose $\mathrm{P}_{i}$ offers $w>w^{C}(\theta)$ to $\mathrm{P}_{-i}$ 's $\theta$-type star when the latter is free in the market. Since $\mathrm{P}_{i}$ makes the best wage offer (that is acceptable to the star) and gets $\pi_{i}(\theta)$ plus a fraction of any renegotiation surplus, the maximum "net" gains from cheating on the tacit understanding are

$$
\pi_{i}(\theta)-w^{C}(\theta)-\lambda_{i}\left[\pi_{i}(\theta)-\pi_{-i}(\theta)\right]
$$

This expression in fact boils down to

$$
w^{N C}(\theta)-w^{C}(\theta)
$$

As a result, in realization $\theta$ principals can sustain collusion along a perfect equilibrium path with cooperation wages $w^{C}(\cdot)$ so long as

$$
w^{N C}(\theta)-w^{C}(\theta) \leq \frac{\delta}{1-\delta} \frac{1}{2}(1-e) \mathbb{E}_{\theta}\left\{w^{N C}(\theta)-w^{C}(\theta)\right\} .
$$


Note that the right-hand side of the above inequality encapsulates the expected discounted value of the long-term loss from deviating on the collusive agreement in the current period. A collusive equilibrium path with cooperation wage schedule $w^{C}(\cdot)$ is therefore sustainable if and only if (3.10) holds for all $\theta$ in $[\underline{\theta}, \bar{\theta}]$. For expositional reasons, we state this result in the following lemma.

Lemma 1 Collusive outcomes (with contracts $\phi_{i}=\left(w_{0}\right.$, exclusive), $i=1,2$, and) with cooperation wage schedule $w^{C}(\cdot)$ can be sustained in a subgame-perfect equilibrium path if and only if

$$
w^{N C}(\theta)-w^{C}(\theta) \leq \frac{\delta}{1-\delta} \frac{1}{2}(1-e) \mathbb{E}_{\theta}\left\{w^{N C}(\theta)-w^{C}(\theta)\right\} \text { for all } \theta \in[\underline{\theta}, \bar{\theta}]
$$

Proof. See Appendix.

The following proposition generalizes the main conclusion of Section 2 by showing that the ability of principals to sustain collusive outcomes is impaired when law courts are more likely to enforce exclusive employment contracts.

Proposition 4 The set of collusive equilibria (with contracts $\phi_{i}=\left(w_{0}\right.$, exclusive), $\left.i=1,2\right)$ is "nonincreasing" in the level of enforcement, e. More specifically;

1. If a non-competitive equilibrium with cooperation wage schedule $w^{C}(\cdot)$ is sustainable when $e=\widehat{e}$, then it is also sustainable if $e \leq \widehat{e}$.

2. For every non-competitive equilibrium with cooperation wage schedule $w^{C}(\cdot)$ that is sustainable when $e=0$, there exists a level of enforcement $e^{*}(w(\cdot))$ such that collusion with cooperation wage schedule $w^{C}(\cdot)$ is not sustainable for $e>e^{*}\left(w^{C}(\cdot)\right)$.

Proof. Point 1. follows from Lemma 1 and the fact that the r.h.s. of (3.11) is decreasing with $e$. Point 2. follows from Lemma 1 and the fact that the r.h.s. of (3.11) is decreasing with $e$ and converges to 0 as $e$ approaches 1 .

We next investigate how the level of enforcement of exclusivity affects stars' equilibrium wages and principals' expected payoffs. This allows us to revisit distributional issues in a more realistic context. To undertake such a comparative-static analysis, we focus on the most profitable outcomes that principals can sustain in a collusive equilibrium path. In this respect, we define the "most profitable collusive equilibrium" as one in which principals tacitly agree to offer free stars the lowest sustainable wage $w^{C}(\theta) \geq w_{0}$ for each $\theta$-type star. ${ }^{25}$

\footnotetext{
${ }^{25}$ This definition implies that in the most profitable equilibrium principals' expected payoffs are the highest among the payoffs in all possible collusive equilibria, but it is slightly stronger than that. For it also entails the existence of a well-defined cooperation wage schedule $w^{C}(\cdot)$ in the most profitable equilibrium.
} 
As a starting point, let us characterize cooperation wages in the most profitable collusive equilibrium that principals can sustain.

Lemma 2 The cooperation wage schedule $w^{C}(\cdot)$ associated with the most profitable collusive equilibrium may be characterized as follows:

$$
w^{C}(\theta)=\left\{\begin{array}{ll}
w_{0} & \text { if } \quad \theta \leq \theta^{*} \\
w^{N C}(\theta)-K & \text { if } \quad \theta>\theta^{*}
\end{array},\right.
$$

for some $\theta^{*} \leq \bar{\theta}$ and $K$ such that $w^{N C}(\theta)-K>w_{0}$ for all $\left.\left.\theta \in\right] \max \left\{\underline{\theta}, \theta^{*}\right\}, \bar{\theta}\right]$.

Moreover, if $e<e^{*}=\frac{3 \delta-2}{\delta}$ the most profitable collusive equilibrium exists and is such that $\theta^{*} \in(\underline{\theta}, \bar{\theta}]$ and $K=w^{N C}\left(\theta^{*}\right)-w_{0}$.

\section{Proof. See Appendix.}

The argument behind Lemma 2 is simple. In the most profitable collusive path, principals pay free stars the lowest wage packet for which the immediate reward for deviating from the agreement is outweighed by the expected discounted value of future punishments. The key feature though is that the gains from cheating covary with the quality of the current star in the market. Effectively, in low states of nature the temptation to cheat is relatively small with respect to the expected value of future punishments (which depends on future realizations of $\tilde{\theta}$ ). Hence principals can sustain $w_{0}$ as a cooperative wage. When principals are faced with a free star of abnormally high quality (a superstar), however, the gains from deviating rise relative to the present value of future punishments. On such occasions incentive compatibility requires that principals pay non-competitive wages above $w_{0}$. That way, the reward for defecting in the current period shrinks. Another interesting implication of Proposition 2 is that for stars of relatively high ability (i.e. in realizations where $\theta>\theta^{*}$ ), the "marginal reward" to ability under the most profitable collusion equilibrium is identical to that under non-collusion. More specifically, whenever $\theta>\theta^{*}$ the non-cooperative wage function $w^{N C}(\theta)$ differs from the cooperation wage schedule $w^{C}(\cdot)$ by just a constant.

The result that in some realizations of $\tilde{\theta}$ principals may find it profitable to collude on wages above $w_{0}$ to diminish the temptation to cheat is reminiscent of Rotermberg and Saloner (1986). In their case, periods of relatively high demand are accompanied by output beyond the joint profit-maximizing level so as to reduce the immediate benefits reaped by a deviating firm. This behavior gives rise to the so-called "price wars during booms". ${ }^{26}$ Here, however, superbly talented stars who are free in the market earn premium wages

\footnotetext{
${ }^{26}$ Snyder (1996) relies on a similar sort of logic to develop a theory explaining discounts for large buyers. In his model, a buyer's countervailing power stems from the fact that he may accumulate a large backlog of unfilled orders and purchase all at once. The off-equilibrium-path strategic threat of using lumpy orders generates "endogenous" booms in demand that once again constrain collusive sellers.
} 
because principals attempt to sustain collusive outcomes. Since cooperation between principals never really breaks down, these outcomes are a sort of "cold wars" for talent.

We now move on to analyze how $e$ affects stars' equilibrium wages along the most profitable collusive equilibrium sustainable by principals. Since Proposition 4 showed that the sustainability of collusion with a given $w^{C}(\cdot)$ depends on the probability of enforcement, we refer to the cooperative wage schedule and the cutoff $\theta^{*}$ associated with the most profitable equilibrium as functions of $e: w^{C}(\cdot, e)$ and $\theta^{*}(e)$, respectively. The next result then follows.

Proposition 5 Suppose that $\theta^{*}(e)<\bar{\theta}$ (i.e., cooperation on the lowest possible wage $w_{0}$ for all $\theta \in[\underline{\theta}, \bar{\theta}]$ is not sustainable in equilibrium). Then, the cooperation wage $w^{C}(\theta, e)$ associated with the most profitable collusive equilibrium is strictly increasing in $e$, for each $\theta \in\left[\max \left\{\underline{\theta}, \theta^{*}(e)\right\}, \bar{\theta}\right]$. Further, if $\theta^{*}(e) \geq \underline{\theta}$ then $\theta^{*}(e)$ is strictly decreasing in e.

Proof. See Appendix.

Proposition 5 establishes that stars' wage packets tend to increase (more specifically, do not decrease) as exclusivity is more tightly enforced by courts. This comparative-static result may seem self-evident, since tighter enforcement of non-compete covenants ultimately means that principals have to pay more to hire their agents exclusively. However, the underlying mechanism at work in our model is much more subtle. When the level enforcement of exclusive contracts increases, collusion becomes more difficult to sustain because future punishments on deviants are less severe. In order to sustain optimal collusive equilibria, principals must therefore permit high-ability stars to earn higher wages and content themselves with lower profits. That way, neither principal finds it profitable to deviate from the agreement.

Figure 2 illustrates the central messages of Propositions 5 and Lemma 2, where we depict the cooperative wage schedule, $w^{C}(\cdot)$, as a function of the quality parameter, $\theta$ (we further assume that $\pi_{i}(\cdot)$ is strictly concave). We consider there a comparative-static exercise for two fixed values of the probability of enforcement, $e^{\prime}>0$ and $e^{\prime \prime}>e^{\prime}$. Note that as $e$ rises, the wage schedule shifts upwards and the cut-off value $\theta^{*}$ plummets in order to fulfil condition (3.11). As a result of the increase in $e$, there are more realizations in which stars are paid "non-competitive" wage packets above $w_{0}$-we stress the word non-competitive because these wages are lower than $w^{N C}(\theta)$.

We can now tackle distributional issues. Particularly, we would like to know what happens to the expected discounted payoffs to stars and principals after a change in the probability of enforcement, $e$. In that connection, the fact that free stars of relatively high ability earn higher equilibrium wages when $e$ goes up implies that they may actually gain from tighter enforcement of non-compete clauses. The flip side, of course, is that superstars are less likely to become free. This is analyzed more formally in the next proposition. 


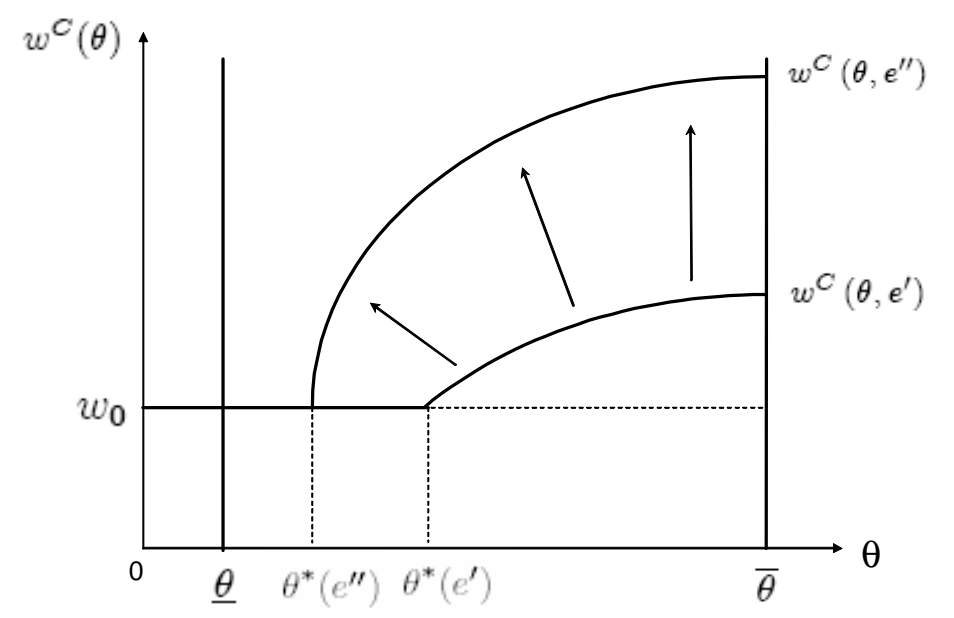

Figure 2: Cooperative wage schedule

Proposition 6 Consider a given probability of enforcement of exclusive contracts, $e^{\prime}$, and suppose that the most profitable collusive equilibrium is such that $\theta^{*}\left(e^{\prime}\right) \in(\underline{\theta}, \bar{\theta})$. If the probability of enforcement rises to $1>e^{\prime \prime}>e^{\prime}$, we have that:

(i) either $\theta^{*}\left(e^{\prime \prime}\right)<\underline{\theta}$ and stars with ability $\theta \in\left[\underline{\theta}, \theta^{*}\left(e^{\prime}\right)\right]$ are better off, or $\theta^{*}\left(e^{\prime \prime}\right) \geq \underline{\theta}$ and stars with ability $\theta \in\left[\underline{\theta}, \theta^{*}\left(e^{\prime \prime}\right)\right]$ earn the same while stars with ability $\theta \in\left(\theta^{*}\left(e^{\prime \prime}\right), \theta^{*}\left(e^{\prime}\right)\right]$ are better off;

(ii) either all stars with ability $\theta \in\left(\theta^{*}\left(e^{\prime}\right), \bar{\theta}\right]$ are better off, or there exists $\varkappa \in\left(\theta^{*}\left(e^{\prime}\right), \bar{\theta}\right)$ such that stars with ability $\theta \in\left(\theta^{*}\left(e^{\prime}\right), \varkappa\right)$ are better off and stars with ability $\theta \in(\varkappa, \bar{\theta}]$ are worse off.

Further, the principals' expected payoffs along the most profitable collusive equilibrium path may decrease with the level of enforcement of exclusivity provisions.

Proof. See Appendix.

When $e$ rises, there are two opposite forces at work. For one thing, a larger fraction of the expected rents created in the market accrue to the colluding principals because stars are free less often. For another thing, collusion is harder to sustain and in some realizations the coordinated wage schedule $w^{C}(\cdot)$ increases. Hence expected rents to the colluding principals falter. The interplay between these two effects ultimately determines whether principals and stars lose or gain from movements in $e$. To illustrate, consider relatively low realizations of $\tilde{\theta}$. On these occasions principals can afford to pay low wages on the collusive path even 
when exclusivity is not enforced. Since the marginal loss from decreasing the likelihood of becoming free stars in the market is low, the second effect dominates and stars are better off when enforcement swells. In relatively high realizations of $\tilde{\theta}$, however, colluding principals need to offer premium wages to free stars. Therefore the marginal loss from being free in the market less often is high and may offset the marginal gain from increases in the coordinated wage bill. In this case, the first effect dominates and superstars are worse off with heightened enforcement.

A consequence of this is that changes in the enforcement parameter need not have the same impact on the well-being of all stars. Particularly, a shift in the legal environment toward stricter exclusivity enforcement may induce a redistribution of expected surplus from top stars to stars of relatively low ability. There also exists a parallel redistribution of wealth between principals and potential stars. An important implication of Proposition 6 is that an increase in the (probabilistic) enforcement level is not necessarily bad for stars and good for principals. Actually exactly the opposite may be true. This conclusion stems from the impact of stricter enforcement on the most profitable collusive equilibria that principals can sustain.

\subsection{Partial Collusion and Star Wars}

In this section, we discuss briefly how our results extend to a simpler form of collusion in which, given a state of nature, principals either abstain from hiring each other's star or engage in fierce competition for the new talent. This sort of collusion is appealing because it requires relatively little coordination and/or communication between principals - the prescribed strategies are less delicate. Thus it is easier to implement in practice. The downside, of course, is that principals no longer choose the most profitable collusive behavior. Hence there is a basic trade-off between simplicity and profitability. While arguably less burdensome as far as strategic coordination is concerned, this scheme raises the average cost of hiring new talent because coordinated behavior coexists with blatant star wars in equilibrium.

Full collusion means principals cooperate in all possible realizations, i.e., they tacitly agree not to poach each other's star irrespective of the latter's ability. When collusive behavior for all $\theta \in[\underline{\theta}, \bar{\theta}]$ ) is not sustainable, however, principals might focus on less ambitious outcomes in which coordination only occurs in some realizations of $\tilde{\theta}$. For example principals may adopt non-competitive conduct if and only if $\theta \in \Theta \subset[\underline{\theta}, \bar{\theta}]$, where $\Theta$ stands for the cooperation set. These outcomes are called perfect equilibria with "partial collusion". In the presence of partial collusion employers bid for new talent whenever $\theta \notin \Theta$, but this competitive behavior is not considered a defection on the tacit agreement. All this leads to fierce competition for superstars because in relatively high realizations of $\tilde{\theta}$, profitable deviations cannot be deterred. Stars' equilibrium wages are therefore either $w_{0}$ or $w^{N C}(\cdot) .{ }^{27}$

\footnotetext{
${ }^{27}$ Thus bidding wars for superstars may occur both on and off-the-equilibrium path. In our model, bidding wars occur onthe-equilibrium path because principals recognize that for some types of stars they are not able to sustain cooperation. This
} 
Consider an equilibrium with partial collusion in which principals behave non-competitively only if $\theta \in \Theta$. This situation corresponds to the following cooperative wage schedule: $w^{C}(\theta)=w_{0}$ if $\theta \in \Theta$ and $w^{C}(\theta)=$ $w^{N C}(\theta)$ if $\theta \notin \Theta$. In consequence, cooperation wages differ from competition wages only when the star's ability $\theta \in \Theta$. The equilibrium sustainability condition of Lemma 1 then becomes

$$
w^{N C}(\theta)-w_{0} \leq \frac{\delta}{1-\delta} \frac{1}{2}(1-e) \mathbb{E}_{\theta}\left\{w^{N C}(\theta)-w_{0} \mid \theta \in \Theta\right\} \times \mathbb{P}_{r}[\theta \in \Theta] \text {, for all } \theta \in \Theta .
$$

Direct inspection shows that when courts are more prone to enforce exclusive contracts, condition (3.12) is less likely to hold. Indeed Proposition 4 implies that the set of collusive equilibria (partial or total collusion) cannot increase with the level of enforcement, $e$. In other words, if an equilibrium with partial collusion and cooperation set $\Theta$ is sustainable when the $e=\widehat{e}$, then it is also sustainable when $e \leq \widehat{e}$.

We now focus on the most profitable collusive equilibrium with partial collusion. Since principals' payoffs are decreasing in stars' wage packets, the payoffs to principals on the equilibrium path increase with the cooperation set (where set $\Theta_{1}$ is said to be larger than set $\Theta_{2}$ if $\Theta_{2} \subseteq \Theta_{1}$ ). Suppose now that a collusive equilibrium with cooperation set $\Theta \neq \varnothing$ exists, and consider an arbitrary $\theta^{\prime} \in \Theta$. Inequality 3.12 is trivially satisfied for $\theta=\theta^{\prime}$. Further, since the l.h.s. of 3.12 is increasing in $\theta$, it must also hold for every $\theta^{\prime \prime}<\theta^{\prime}$. This observation, together with the fact that in the presence of partial collusion principals' payoffs increase with the size of the supportive cooperation set, dictates that in the most profitable equilibrium principals cooperate whenever $\theta \leq \sup \Theta .{ }^{28}$ Consequently, the cooperation set of the most profitable equilibrium with partial collusion is of the form $\left[\underline{\theta}, \theta^{*}(e)\right]$, for some $\theta^{*}(e) \in[\underline{\theta}, \bar{\theta}]$ - principals cooperate for stars of relatively low ability but compete fiercely for top quality talent.

The sustainability condition for the most profitable equilibrium is then given by

$$
w^{N C}(\theta)-w_{0} \leq \frac{\delta}{1-\delta} \frac{1}{2}(1-e) E_{\theta}\left\{w^{N C}(\theta)-w_{0} \mid \theta \in \Theta\right\} \times F\left(\theta^{*}(e)\right)
$$

for all $\theta \leq \theta^{*}(e)$. When the cutoff $\theta^{*}(e)$ lies inside the set $[\underline{\theta}, \bar{\theta}]$, (3.13) has to hold with equality. In such circumstances, an upward shift in the enforcement level from $e$ to $e^{\prime}$ triggers a decrease in the r.h.s. of (3.13) and therefore $\theta^{*}\left(e^{\prime}\right)<\theta^{*}(e)$.

The aforementioned implies that heightened enforcement of exclusivity provisions leads to more realizations with star wars. Competition for the marginal stars - i.e. those within $\left(\theta^{*}\left(e^{\prime}\right), \theta^{*}(e)\right]$ - increases, and is different from the mechanism that generates price wars in Green and Porter (1984). In Green and Porter (1984), price wars occur on-the-equilibrium path because of an informational problem: when firms observe a low market price, they do not know whether that is due to a negative shock in the demand or to a deviation by one of the other firms. Thus, to make collusion sustainable, a punishment always follows observation of a low market price (even when that is exclusively due to an exogenous demand fluctuation).

${ }^{28}$ The inequality is not strict because the l.h.s. of the inequality in (3.12) is continuous in $\theta$. Thus, if condition (3.12) is satisfied then it is also satisfied for $\sup \Theta$. 
their expected earnings unambiguously go up. Stars with ability above $\theta^{*}(e)$ are clearly worse off: their noncollusive wages do not change but they are less likely to become free talent. Stars with ability $\theta \in\left[\underline{\theta}, \theta^{*}\left(e^{\prime}\right)\right]$ neither lose nor win, and when $\theta^{*}(e)$ is sufficiently close to $\bar{\theta}$ principals are worse off after the change.

We summarize the main results of this section in the following proposition.

Proposition 7 In the most profitable partial collusive equilibrium outcome, principals avert competition in relatively low states of nature (i.e. stars with ability below $\theta^{*}(e)$ ) and compete for the superstars (i.e. stars with ability above $\left.\theta^{*}(e)\right)$.

If $\theta^{*}(e) \in(\underline{\theta}, \bar{\theta})$ and courts become more prone to enforce exclusivity, then the superstars are worse off while the stars with ability $\theta \in\left[\underline{\theta}, \theta^{*}(e)\right]$ are better off. All other stars are unaffected. In addition, there are situations in which principals are worse off after the increase in e.

Realistically, with this milder form of collusion star wars occur even in the equilibrium path. Note also that heightened enforcement of exclusivity leads to a more equitable distribution of rewards across stars: a redistribution of rents takes place from premium talent to stars of lower ability.

\subsection{Exclusive Superstars, Non-Exclusive Goodish Stars}

This section deals with asymmetric information in the context of fully collusive outcomes. In particular, suppose that when principal and agent meet they observe the latter's ability, $\theta_{i}$, but principals know neither the ability of the agent hired by the his rival nor the identity of the star in the market. As in previous sections, this uncertainty is resolved after the initial contracting stage. Thus, think of $\theta$ as the agent's "potential" which is realized only if she becomes a star.

Consider a collusive (subgame-perfect) equilibrium with cooperation wage schedule $w^{C}($.$) . If \mathrm{P}_{i}$ is matched with a $\theta$-type agent for whom $w^{C}(\theta)=w_{0}$, exclusivity is irrelevant because $\mathrm{P}_{i}$ anticipates that in equilibrium $\mathrm{P}_{-i}$ will not poach his star. When matched with a $\theta$-type agent for whom $w^{C}(\theta)>w_{0}$, however, the principal proposes exclusivity to the agent. Effectively $\mathrm{P}_{i}$ knows that if his agent becomes a free star, $\mathrm{P}_{-i}$ will cooperate only if the wage is greater than or equal to $w^{C}(\theta)$. Otherwise $\mathrm{P}_{-i}$ 's gains from cheating on the agreement and poaching the superstar outweigh the cost. Thus, when faced with uniquely talented individuals, principals are better off proposing exclusive contracts to them.

The above argument is formalized in the following proposition.

Proposition 8 Suppose that principals know the ability of the agents they are matched with and that $e>0$. Then, in the most profitable collusive equilibrium to principals, a principal is strictly better off proposing an exclusive contract to an agent if and only if the agent's ability $\theta>\theta^{*}(e)$. 
A testable implication is that only superstars are bounded by exclusivity provisions. ${ }^{29}$ Since uniquely talented stars earn premium wages when they are free in the market, on these occasions exclusivity enables principals to hold a tighter grip on hiring costs. In the case of less outstanding talent, writing exclusive contracts proves too costly because coordination on $w_{0}$ is feasible even when these stars are free in the market.

Another prediction of the above analysis is that exclusive agreements are rampant precisely when courts are more likely to enforce them. While this result seems intuitive, the underlying mechanism at work deserves some attention. Exclusive contracts are more frequently used not because they are necessarily more effective, but because collusive outcomes are harder to sustain and principals fall back on other ways to appropriate the rents created by their stars.

\section{Concluding Remarks}

In this paper we argue that stricter legal enforcement of exclusive (employment) relationships may hinder collusive behavior among firms that compete for the procurement of a scant valuable asset (e.g., talent). This stands in sharp contrast with the commonly held view that exclusivity provisions facilitate collusion (see, e.g., Rey and Stiglitz (1995)). Thus, in the context of this paper, a stricter enforcement of exclusive employment agreements may promote competition and consequently enhance efficiency. This effect can have repercussions well beyond the specific labor/talent market where the exclusive contracts are written - when firms interact in many markets simultaneously, breaking down collusion in the market for talent may induce competitive behavior in all markets.

Based on the derived relationship between the level of legal enforcement of exclusive contracts and firms' ability to sustain collusive, we draw a number of implications both for equilibrium (exclusive) contracts and for redistributive effects of changes in the enforcement of exclusivity.

First, we show that when there exists private information at the contracting stage, exclusive contracts will only be written with those superstars that locate at the top end of quality distribution. So, the paper predicts a positive correlation between frequency of exclusive contracts and employee's quality/ability. This prediction is consistent with the fact that we tend to observe more frequently exclusive contracts with highranked workers in firms (e.g., CEOs and other top managers) than with low ranked employees. Second, we demonstrate in the paper that firms will rely more heavily on exclusive contracts when those contracts are more likely to be enforced. While this conclusion seems trivial, the underlying mechanism at work is quite subtle: as higher enforcement results in fewer collusive equilibrium outcomes, principals have more

\footnotetext{
${ }^{29}$ We implicitly assume that when indifferent between proposing an exclusive contracts and non-exclusive contract, a principal proposes a non-exclusive contract.
} 
incentives to write exclusive contracts as a safeguard against expropriation of the rents that their stars may generate in the future. Third, we show that an increase in the probability of enforcement of exclusivity deals leads to a redistribution of expected rents from premium stars to average-quality stars. This is because increasing the enforcement of exclusive contracts has two opposite effects on stars payoffs. On the one hand, stars lose because they are free less often, on the other hand their wages when they are free go up because coordination is harder to sustain. For stars of exceptional talent the first effect tends to dominate, whereas for stars of moderate talent the second effect is the dominant. Thus, when enforcement increases there is redistribution of surplus from very talented stars to less talented ones. One can also show that principals can be worse off following an increase in exclusivity enforcement. Insofar as courts attach value to a more equitable distribution of wealth across individuals, raising the enforcement level may then produce valuable redistributive effects. 


\section{Appendix}

\section{A.1. Agents with bargaining power at the outset}

The setting is essentially similar to the one considered in Section 2, but we assume that in any given match principal and agent make take-it-or-leave-it contract offers with probability $\alpha$ and $1-\alpha$, respectively. The situation considered in the main text thus corresponds to $\alpha=1$. In this formulation, $\alpha$ captures the bargaining strength of principals - as $\alpha$ becomes smaller, potential stars appropriate a larger proportion of the surplus created in the market. This simple model has been used by De Fraja and Sákovics (2001) and Rey and Tirole (2005), among others. We further suppose that if a contract offer is rejected, the corresponding agent returns to the pool of unmatched agents whilst the corresponding principal remains inactive for the remainder of the stage game.

As always, we begin by examining the competitive equilibrium of the one-shot game in which no collusion occurs. If $\mathrm{P}_{i}, i \in\{1,2\}$, has the chance to make a take-it-or-leave-it offer to the agent, the optimal contract is $\phi_{i}=\left(w_{0}\right.$, exclusive $)$. On the other hand, if the potential star has the chance to make a take-it-or-leave-it offer to the principal, the optimal contract may be $\phi_{A}=\left(w_{0}\right.$, non-exclusive $)$ or $\phi_{A}^{\prime}=\left(\frac{w_{0}+e \pi}{1+e}\right.$, exclusive $) .{ }^{30}$ To understand the latter, recall that with either contractual arrangement the agent reaps all the expected benefits brought about through her presence in the market. Hence if the potential stars offers exclusionary rights over his future talent he can demand a wage packet $w^{N C}$ such that $\frac{1}{2} e\left(\pi-w^{N C}\right)+\frac{1}{2}\left(w_{0}-w^{N C}\right)=0$, that is, $w^{N C}=\left(e \pi+w_{0}\right) /(1+e)$. Note that every take-it-or-leave-it offer leaves the responding party indifferent between accepting and not accepting.

Hence, at the beginning of a stage game $\mathrm{P}_{i}$ 's expected payoff for that period is as follows

$$
\begin{aligned}
\tilde{\sigma}_{i}^{N C} & =\alpha \frac{1}{2} e\left(\pi-w_{0}\right)+(1-\alpha) \times 0 \\
& =\alpha \frac{1}{2} e\left(\pi-w_{0}\right)
\end{aligned}
$$

In an infinite-horizon setting in which principals can sustain collusive outcomes, their discounted expected payoffs along the most profitable (or the "best") non-competitive equilibrium path is given by

$$
\frac{\delta}{1-\delta} \alpha \frac{1}{2}\left(\pi-w_{0}\right)
$$

Effectively it is as if principals took turns in collecting expected "monopoly" rents, which in turn depend on the distribution of bargaining power. A principal's gain from cheating on the collusive agreement, i.e. the reward for luring the star away from the other principal, is now given by

$$
\pi-\tilde{w}
$$

\footnotetext{
${ }^{30}$ If agents were risk averse, though, they would strictly prefer to offer principals exclusive contracts instead of non-exclusive ones.
} 


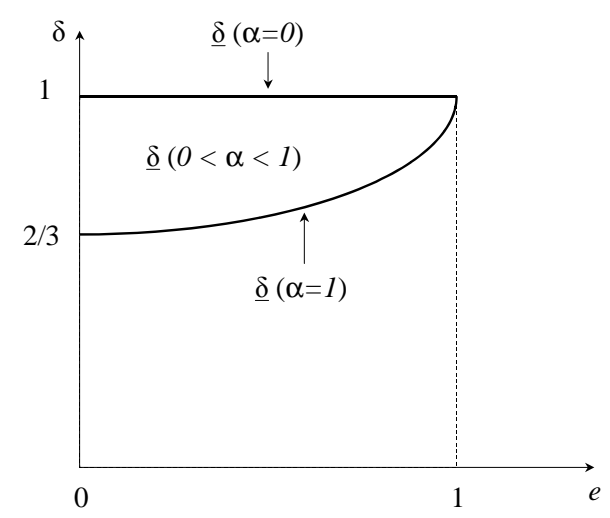

Figure 3: Relationship between $e$ and $\delta$, for different $\alpha$.

where $\tilde{w}$ is the minimum wage offer that induces the new talent to switch principals. Presently, the optimal wage packet that needs to be offered by a deviating principal can take one out of two possible values

$$
\begin{aligned}
\tilde{w} & =w_{0}, \text { or } \\
\tilde{w} & =\frac{1}{2}\left(\pi+w_{0}\right)
\end{aligned}
$$

depending on whether the principal or the (non-exclusive) star had a chance to make an offer at the contracting stage. In effect principals always offer a wage equal to $w_{0}$ whereas agents can demand a reward $w^{C}$ such that $\left(\pi-w^{C}\right) / 2+\left(w_{0}-w^{C}\right) / 2=0$, that is, $w^{C}=\left(\pi+w_{0}\right) / 2$. It is easy to see that $w^{C}>w^{N C}$ and that the immediate benefit for the deviating principal, $\pi-\tilde{w}$, is always positive.

From (4.1) and (4.2), we may conclude that $\mathrm{P}_{i}$ would "never" deviate from the collusive agreement if

$$
\pi-w_{0}<\frac{\delta}{1-\delta} \frac{1}{2} \alpha(1-e)\left(\pi-w_{0}\right)
$$

that is, if

$$
e<\frac{\delta(2+\alpha)-2}{\delta \alpha}=\tilde{e}
$$

The critical discount factor $\underline{\delta}=2 /[2+\alpha(1-e)]$ and its positive relationship with the enforcement level $e$ is depicted in Figure 3. Evidently, as $\alpha$ increases the set of potential values of $e$ for which principals can sustain non-competitive behavior expands. That is, $\partial \tilde{e} / \partial \alpha>0$. This is because the gain from defection remains the same whereas the discounted value of the future losses goes up (see 4.3). As a result, when $\alpha$ increases principals can sustain collusion even with stricter legal enforcement of exclusive contracts. Another way to put it is that as $\alpha$ approaches zero, collusive outcomes are impossible to sustain in a subgame-perfect 
equilibrium because the gains from cheating are bounded away from zero whereas the discounted payoffs along the collusive path tend to zero. The point we want to make though is that for any $\alpha>0$, the sustainability of collusive behavior between principals in the market for new talent decreases with $e$. This is precisely the insight brought into the foreground in Section 2.

\section{A.2. Three-way bargaining ex post}

The purpose of this section is to show that the qualitative conclusion of Proposition 1 carries over to a slightly more complicated - albeit perhaps also more realistic - environment in which the star has some bargaining power and can always force a wage renegotiation ex post. To do this, we focus on the case of equally productive principals and stars considered in Section 2, and rely on the three-party bargaining model pioneered by Segal and Whinston (2000) and furthered by Segal (2003). For notational convenience, we assume throughout that $w_{0}$ and the revenue created by a standard agent equal zero.

Segal and Whinston's bargaining solution guarantees efficiency. In addition, player $j$ 's ex post payoff consists of a non-negatively weighted linear combination of his or her marginal contributions to the different coalitions that can potentially be formed. So let the constant $\alpha_{j}^{\Omega}$ represent the weight on player $j$ 's marginal contribution to coalition $\Omega$ in the player's payoff function. ${ }^{31}$ Notice that, in our model, all coalitions in which there is only one player and the coalition containing the two principals produce a surplus of zero.

Consider first each period of the punishment phase. When $\mathrm{P}_{i}$ holds enforceable exclusive rights over the star in the market, the parties' bargaining payoffs are as follows:

$$
\begin{aligned}
\sigma_{i}^{E} & =\left(\alpha_{i}^{-i, s}+\alpha_{i}^{s}\right) \pi, \\
\sigma_{-i}^{E} & =0, \\
\sigma_{s}^{E} & =\left(\alpha_{s}^{i,-i}+\alpha_{s}^{i}\right) \pi,
\end{aligned}
$$

where the letter $s$ refers to the star. These payoff functions reflect the following considerations. When $\mathrm{P}_{i}$ joins the coalition $\Omega=\left\{\mathrm{P}_{-i}, s\right\}$, his marginal contribution is $\pi$ because the star may not work for other principals. The same marginal contribution obtains when $\mathrm{P}_{i}$ joins the coalition $\Omega=\{s\}$. When $\mathrm{P}_{i}$ has exclusive rights over the star, $\mathrm{P}_{-i}$ 's marginal contribution to coalition $\Omega=\{s\}$ vanishes so his final payoff is zero. Finally, the star's payoff function is the mirror image of $\mathrm{P}_{i}$ 's.

When the star is non-exclusive, her bargaining position vis-à-vis the principals improves. Concretely;

$$
\begin{aligned}
\sigma_{i} & =\alpha_{i}^{s} \pi, \\
\sigma_{-i} & =\alpha_{-i}^{s} \pi, \\
\sigma_{s} & =\left(\alpha_{s}^{i,-i}+\alpha_{s}^{i}+\alpha_{s}^{-i}\right) \pi .
\end{aligned}
$$

\footnotetext{
${ }^{31}$ With appropriate parameterization, this bargaining framework may encompass as special cases both cooperative and noncooperative solutions that have been frequently used in the economics literature, e.g., the Shapley value.
} 
The key difference between (4.4) and (4.5) is that in the latter case the members of coalition $\Omega=\left\{\mathrm{P}_{-i}, s\right\}$ may trade and therefore their payoffs go up. By the same token, $\mathrm{P}_{i}$ 's bargaining payoff plummets. Since aggregate payoffs should always equal the surplus generated by the grand coalition of all players, the parameters $\alpha_{j}^{\Omega}$ must also satisfy the following adding-up restrictions:

$$
\alpha_{i}^{-i, s}+\alpha_{-i}^{i, s}+\alpha_{s}^{i,-i}=1, \quad \alpha_{s}^{i}+\alpha_{i}^{s}=\alpha_{-i}^{i, s}, \quad \text { and } \quad \alpha_{s}^{-i}+\alpha_{-i}^{s}=\alpha_{i}^{-i, s}
$$

Given the symmetry embodied in our model, it seems natural to assume that $\alpha_{s}^{i}=\alpha_{s}^{-i}$ and $\alpha_{i}^{s}=\alpha_{-i}^{s}$, which implies that $\alpha_{-i}^{i, s}=\alpha_{i}^{-i, s}$. Hence, after a deviation, the discounted stream of payoff to $\mathrm{P}_{i}$ is thus given by

$$
\frac{\delta}{1-\delta} \frac{1}{2}\left[e\left(\alpha_{i}^{-i, s}+\alpha_{i}^{s}\right) \pi+(1-e) \alpha_{i}^{s} \pi+(1-e) \alpha_{i}^{s} \pi\right]
$$

which boils down to

$$
\frac{\delta}{1-\delta} \frac{1}{2}\left[2 \alpha_{i}^{s}+e\left(\alpha_{i}^{-i, s}-\alpha_{i}^{s}\right)\right] \pi
$$

Each period, the principal who breeds the star, $\mathrm{P}_{i}$ say, gets a share $\alpha_{i}^{s}$ of total surplus independently of the probability that exclusivity provisions are enforced. He also collects $\alpha_{i}^{-i, s} \pi$ whenever the exclusive contract is enforced whereas the principal who did not breed the star collects $\alpha_{-i}^{s} \pi$ whenever the exclusive contract is not enforced. What should be stressed about (4.6) is that it is non-decreasing in the probability of court enforcement of exclusivity provisions, because $\alpha_{i}^{-i, s} \geq \alpha_{i}^{s}$.

Next, consider each period of the collusive path. Since principals avoid hiring each other's star irrespective of whether or not the latter is free in the market, when $\mathrm{P}_{i}$ breeds the star the bargaining solution reduces to

$$
\begin{aligned}
\sigma_{i}^{C} & =\left(\alpha_{i}^{-i, s}+\alpha_{i}^{s}\right) \pi, \\
\sigma_{-i}^{C} & =0, \\
\sigma_{s}^{C} & =\left(\alpha_{s}^{i,-i}+\alpha_{s}^{i}\right) \pi .
\end{aligned}
$$

Consequently the equilibrium discounted payoff to each colluding principal equals

$$
\frac{\delta}{1-\delta} \frac{1}{2}\left(\alpha_{i}^{-i, s}+\alpha_{i}^{s}\right) \pi .
$$

From (4.6) and (4.7), we may compute the expected discounted loss of future profits as a result of cheating on the implicit understanding between principals. These long-term losses amount to

$$
\frac{\delta}{1-\delta} \frac{1}{2}(1-e)\left(\alpha_{i}^{-i, s}-\alpha_{i}^{s}\right) \pi
$$

The above expression is non-negative and decreasing in $e$, whereas the short-term gains from deviating are independent of $e$. Hence the qualitative effect of an increase in the probability of exclusivity enforcement on principals' ability to sustain collusive outcomes is as in Section 2. 


\section{A.2. Proofs}

Proof. (of Lemma 2) We start by the first part of the lemma. Let $K$ denote the value of the punishment associated to a deviation from the most profitable equilibrium. Because in the most profitable equilibrium cooperation wages $w^{C}(\cdot)$ must be the lowest among those that are sustainable, $w^{C}(\theta)$ must equal $w_{0}$ if $\theta$ is such that $w^{N C}(\theta)-w_{0} \leq K$ and must satisfy $w^{N C}(\theta)-w^{C}(\theta)=K$ if otherwise. The result then follows from letting $\theta^{*}<\underline{\theta}$ if $w^{N C}(\underline{\theta})-w_{0}>K, \theta^{*}=\bar{\theta}$ if $w^{N C}(\bar{\theta})-w_{0} \leq K$ and $\theta^{*}$ such that $w^{N C}\left(\theta^{*}\right)-w_{0}=K$ (which by continuity of $w^{N C}(\cdot)$ exists) if otherwise, and using the fact that $w^{N C}(\theta)$ is increasing in $\theta$.

We next focus on the case in which $e<e^{*}$ and prove the second part of the lemma. Suppose first that

$$
\frac{1}{2} \frac{\delta}{1-\delta}(1-e) \geq \frac{w^{N C}(\bar{\theta})-w_{0}}{\mathbb{E}_{\theta}\left\{w^{N C}(\theta)-w_{0}\right\}} .
$$

Continuity of $F($.$) implies that f($.$) is atomless, which in turn implies that the r.h.s. of (4.8) is strictly bigger$ than one. Thus, (4.8) is equivalent to $e \leq e_{0}$, where $e_{0}<e^{*}$. Condition (4.8) is also equivalent to condition (3.11) in Lemma 1 when cooperation wages are $w^{C}(\theta)=w_{0}$ for all $\theta \in[\underline{\theta}, \bar{\theta}]$. Therefore, it implies that a collusive equilibrium with those cooperation wages is sustainable. If an equilibrium with cooperation wages $w^{C}(\theta)=w_{0}$ for all $\theta \in[\underline{\theta}, \bar{\theta}]$ is sustainable, then it is the most profitable to principals. Thus, in this case, such equilibrium exists and is characterized by a wage schedule satisfying $w^{C}(\theta)=w_{0}$ for all $\theta \in[\underline{\theta}, \bar{\theta}]$, which in the statement of the Lemma correspond to the case of $\theta^{*}=\bar{\theta}$.

Suppose now that

$$
1<\frac{1}{2} \frac{\delta}{1-\delta}(1-e)<\frac{w^{N C}(\bar{\theta})-w_{0}}{\mathbb{E}_{\theta}\left\{w^{N C}(\theta)-w_{0}\right\}},
$$

i.e., $e_{0}<e<e^{*}$. Let $Z$ denote the value of a punishment following a deviation. Take it as exogenous for a moment. Given $Z$, let $\widehat{\theta}$ be the maximum talent for which cooperation wage $w_{0}$ is sustainable, i.e.,

$$
w^{N C}(\widehat{\theta})-w_{0}=Z
$$

Given punishment $Z$, the optimal cooperation wages from the principals' perspective (that are sustainable) are $w^{C}(\theta)=w_{0}$ if $\theta \leq \widehat{\theta}$ and $w^{C}(\theta)=w^{N C}(\theta)-Z$ if $\theta>\widehat{\theta}$, since these wages are the lowest for which a deviation is not profitable. Now, given these optimal cooperation wages, we can obtain the value of the punishment, which depends on the cutoff $\widehat{\theta}$. Specifically,

$$
Z(\widehat{\theta})=\frac{1}{2} \frac{\delta}{1-\delta}(1-e)\left[\int_{\underline{\theta}}^{\widehat{\theta}}\left(w^{N C}(\theta)-w_{0}\right) d F(\theta)+(1-F(\widehat{\theta}))\left(w^{N C}(\widehat{\theta})-w_{0}\right)\right] .
$$

Thus, we have a mapping from the space of possible punishments into itself: a given punishment implies an optimal wage schedule defined by the cutoff $\theta^{*}$ obtained from (4.10), which in turn implies a new punishment from (4.11). The fixed points of this mapping correspond to collusive equilibria of our game. The fixed 
point with the highest $Z$ corresponds to the most profitable collusive equilibrium. We now show that a fixed point exists. Specifically, we show that exists a $\widehat{\theta} \in(\underline{\theta}, \bar{\theta})$ for which (4.10) and (4.11) hold. Define $h\left(\theta^{\prime}\right)=w^{N C}\left(\theta^{\prime}\right)-w_{0}-Z\left(\theta^{\prime}\right)$. We need to show that exists a $\theta^{\prime} \in(\underline{\theta}, \bar{\theta})$ such that $h\left(\theta^{\prime}\right)=0$. Using (4.11), we obtain that

$$
h(\underline{\theta})=\left[w^{N C}(\underline{\theta})-w_{0}\right]\left(1-\frac{1}{2} \frac{\delta}{1-\delta}(1-e)\right) .
$$

The expression in square brackets is positive, since $w^{N C}(\underline{\theta})=\lambda_{1} \pi_{2}(\underline{\theta})+\lambda_{2} \pi_{1}(\underline{\theta})$ and $\pi_{i}(\underline{\theta})>w_{0}, i \in\{1,2\}$. By the first inequality in (4.9), the expression in the curved brackets is negative. Therefore $h(\underline{\theta})<0$. In a similar way, we obtain that

$$
h(\bar{\theta})=\left[w^{N C}(\bar{\theta})-w_{0}\right]-\frac{1}{2} \frac{\delta}{1-\delta}(1-e) \int_{\underline{\theta}}^{\bar{\theta}}\left(w^{N C}(\theta)-w_{0}\right) d F(\theta),
$$

which by the second inequality in (4.9) is positive. Since $h(\underline{\theta})$ is negative, $h(\bar{\theta})$ is positive and $h(\cdot)$ is continuous, it follows from the Intermediate Value Theorem that exist $\theta^{\prime} \in(\underline{\theta}, \bar{\theta})$ such that $h\left(\theta^{\prime}\right)=0$. Moreover, from continuity of $h(\cdot)$ and the fact that $h(\bar{\theta})$ is positive, it follows that the set $\left\{\theta^{\prime} \in(\underline{\theta}, \bar{\theta})\right.$ : $\left.h\left(\theta^{\prime}\right)=0\right\}$, which is nonempty, has a maximum. Since $Z(\cdot)$ is increasing, this maximum corresponds to the most profitable collusive equilibrium. Let $\theta^{*}=\max \left\{\theta^{\prime} \in(\underline{\theta}, \bar{\theta}): h\left(\theta^{\prime}\right)=0\right\}$. By construction, cooperation wages associated to most collusive equilibrium satisfy $w^{C}(\theta)=w_{0}$ if $\theta \leq \theta^{*}$, and $w^{C}(\theta)=w^{N C}(\theta)-Z\left(\theta^{*}\right)=$ $w^{N C}(\theta)-w^{N C}\left(\theta^{*}\right)+w_{0}$, where the second equality follows from (4.10). Further, $\theta^{*}>\underline{\theta}$. This completes the proof.

Proof. (of Proposition 5) We start by showing that $w^{C}(\theta, e)$ is strictly increasing in $e$ for each $\theta \in$ $\left[\max \left\{\underline{\theta}, \theta^{*}(e)\right\}, \bar{\theta}\right]$. Consider first an arbitrary $\left.\left.\theta^{\prime} \in\right] \max \left\{\underline{\theta}, \theta^{*}(e)\right\}, \bar{\theta}\right]$. From Lemma 2 , it follows that $w^{C}\left(\theta^{\prime}, e\right)>w_{0}$. Since in the most profitable equilibrium, principals pay to a free agent the lowest wage for which a deviation is not profitable, then (3.10) must hold with equality for $\theta=\theta^{\prime}$, i.e.,

$$
w^{N C}\left(\theta^{\prime}\right)-w^{C}\left(\theta^{\prime}, e\right)=\frac{\delta}{1-\delta} \frac{1}{2}(1-e) E_{\theta}\left\{w^{N C}(\theta)-w^{C}(\theta, e)\right\} .
$$

Note that, given enforcement level $e$, the r.h.s. of (4.12) is the maximum of the r.h.s. of (3.10) within the set of cooperation wage schedules $w^{C}(\cdot)$ that are sustainable in a collusive equilibrium. This is because the r.h.s. of (3.10) corresponds to the difference between a principal's discounted payoff along the collusive path and along the punishment phase and the latter does not depend on cooperation wages. We can then conclude that among all the wage schedules $w^{C}(\cdot)$ sustainable in a collusive equilibrium when enforcement level is $e, E_{\theta}\left\{w^{N C}(\theta)-w^{C}(\theta)\right\}$ is maximal when $w^{C}(\cdot)=w^{C}(\cdot, e)$. From this and from the fact that the set of collusive equilibria is non-increasing in $e$ (established in Proposition 4), it follows that for $e^{\prime}>e$

$$
E_{\theta}\left\{w^{N C}(\theta)-w^{C}\left(\theta, e^{\prime}\right)\right\} \leq E_{\theta}\left\{w^{N C}(\theta)-w^{C}(\theta, e)\right\}
$$


which implies that

$$
\frac{\delta}{1-\delta} \frac{1}{2}\left(1-e^{\prime}\right) E_{\theta}\left\{w^{N C}(\theta)-w^{C}\left(\theta, e^{\prime}\right)\right\}<\frac{\delta}{1-\delta} \frac{1}{2}(1-e) E_{\theta}\left\{w^{N C}(\theta)-w^{C}(\theta, e)\right\} .
$$

From (4.12), we obtain that cooperation wage $w^{C}\left(\theta^{\prime}, e\right)$ is not sustainable when enforcement level is $e^{\prime}$ and consequently $w^{C}\left(\theta^{\prime}, e^{\prime}\right)>w^{C}\left(\theta^{\prime}, e\right)$.

Consider now the case in which $\theta^{\prime}=\max \left\{\underline{\theta}, \theta^{*}(e)\right\}$. If $\underline{\theta}>\theta^{*}(e)$, then the proof is identical to when $\left.\left.\theta^{\prime} \in\right] \max \left\{\underline{\theta}, \theta^{*}(e)\right\}, \bar{\theta}\right]$. If $\underline{\theta} \leq \theta^{*}(e)$, then by Lemma $2 w^{C}\left(\theta^{*}(e), e\right)=w_{0}$. Since $\theta^{*}(e)<\bar{\theta}$, optimality of cooperation wage schedule $w^{C}(\cdot, e)$ implies that

$$
w^{N C}\left(\theta^{*}(e)\right)-w_{0}=\frac{\delta}{1-\delta} \frac{1}{2}(1-e) E_{\theta}\left\{w^{N C}(\theta)-w^{C}(\theta, e)\right\} .
$$

(4.14) together with (4.13) (which also holds in this case) imply two things. First, they imply that $w^{C}\left(\theta^{*}(e), e^{\prime}\right)>w^{C}\left(\theta^{*}(e), e\right)$, which concludes the proof that $w^{C}(\theta, e)$ is strictly increasing in $e$ for each $\theta \in\left[\max \left\{\underline{\theta}, \theta^{*}(e)\right\}, \bar{\theta}\right]$. Second, they imply that $\theta^{*}\left(e^{\prime}\right)<\theta^{*}(e)$ because $w^{N C}(\theta)$ is a increasing function of $\theta$, which establishes that $\theta^{*}(e)$ is decreasing in $e$. This concludes the proof.

Proof. (of Proposition 6) Let $\sigma_{s}^{C}(\theta, e)$ denote the expected payoff (along the most profitable collusive equilibrium to principals) of a $\theta$-type star when enforcement level is $e$. Thus,

$$
\sigma_{s}^{C}(\theta, e)=e w_{0}+(1-e) w^{C}(\theta, e)
$$

Using (4.15) and performing some algebra manipulation the difference $\sigma_{s}^{C}\left(\theta, e^{\prime \prime}\right)-\sigma_{s}^{C}\left(\theta, e^{\prime}\right)$ can be written as

$$
\left(e^{\prime \prime}-e^{\prime}\right)\left[w_{0}-w^{C}\left(\theta, e^{\prime}\right)\right]+\left(1-e^{\prime \prime}\right)\left[w^{C}\left(\theta, e^{\prime \prime}\right)-w^{C}\left(\theta, e^{\prime}\right)\right] .
$$

Consider first a star with ability $\theta \in\left[\underline{\theta}, \theta^{*}\left(e^{\prime}\right)\right]$. From Lemma 2 it follows that $w^{C}\left(\theta, e^{\prime}\right)=w_{0}$, which implies that

$$
\sigma_{s}^{C}\left(\theta, e^{\prime \prime}\right)-\sigma_{s}^{C}\left(\theta, e^{\prime}\right)=\left(1-e^{\prime \prime}\right)\left[w^{C}\left(\theta, e^{\prime \prime}\right)-w_{0}\right] .
$$

By Lemma 2 again, $w^{C}\left(\theta, e^{\prime \prime}\right)=w_{0}$ if $\theta \leq \theta^{*}\left(e^{\prime \prime}\right)$ and $w^{C}\left(\theta, e^{\prime \prime}\right)>w_{0}$ if otherwise, which implies that $\sigma_{s}^{C}\left(\theta, e^{\prime \prime}\right)-\sigma_{s}^{C}\left(\theta, e^{\prime}\right)=0$ if $\theta \leq \theta^{*}\left(e^{\prime \prime}\right)$ and $\sigma_{s}^{C}\left(\theta, e^{\prime \prime}\right)-\sigma_{s}^{C}\left(\theta, e^{\prime}\right)>0$ if otherwise. This establishes point (i) of the proposition.

Consider now a star with ability $\theta \in\left[\theta^{*}\left(e^{\prime}\right), \bar{\theta}\right]$. By Lemma $2, w^{C}(\theta, e)=w_{0}+w^{N C}(\theta)-w^{N C}\left(\theta^{*}(e)\right)$ for both when $e=e^{\prime}$ and when $e=e^{\prime \prime}$. Substituting $w^{C}\left(\theta, e^{\prime}\right)$ and $w^{C}\left(\theta, e^{\prime \prime}\right)$ by these expressions in (4.16), we obtain

$$
\left(e^{\prime \prime}-e^{\prime}\right)\left[w^{N C}\left(\theta^{*}\left(e^{\prime}\right)\right)-w^{N C}(\theta)\right]+\left(1-e^{\prime \prime}\right)\left[w^{N C}\left(\theta^{*}\left(e^{\prime}\right)\right)-w^{N C}\left(\theta^{*}\left(e^{\prime \prime}\right)\right)\right] .
$$

The second term in (4.17) is strictly positive, since $\theta^{*}\left(e^{\prime}\right)>\theta^{*}\left(e^{\prime \prime}\right)$ and $w^{N C}($.$) is an increasing function.$ Since $w^{N C}($.$) is also continuous, the first term in (4.17) is close to zero for values of \theta$ close to $\theta^{*}\left(e^{\prime}\right)$, which 
implies that $\sigma_{s}^{C}\left(\theta, e^{\prime \prime}\right)-\sigma_{s}^{C}\left(\theta, e^{\prime}\right)>0$ if $\theta$ is bigger than $\theta^{*}\left(e^{\prime}\right)$ but close to it. If $\sigma_{s}^{C}\left(\bar{\theta}, e^{\prime \prime}\right)-\sigma_{s}^{C}\left(\bar{\theta}, e^{\prime}\right)<0$, then from the facts that $w^{N C}($.$) is increasing and continuous it follows that exists \varkappa \in\left(\theta^{*}\left(e^{\prime}\right), \bar{\theta}\right)$ such that $\sigma_{s}^{C}\left(\theta, e^{\prime \prime}\right)-\sigma_{s}^{C}\left(\theta, e^{\prime}\right)>0$ iff $\theta \in\left(\theta^{*}\left(e^{\prime}\right), \varkappa\right)$ and $\sigma_{s}^{C}\left(\theta, e^{\prime \prime}\right)-\sigma_{s}^{C}\left(\theta, e^{\prime}\right)<0$ iff $\theta \in(\varkappa, \bar{\theta}]$. If not, then $\sigma_{s}^{C}\left(\theta, e^{\prime \prime}\right)-\sigma_{s}^{C}\left(\theta, e^{\prime}\right)>0$ for all $\theta \in\left[\theta^{*}\left(e^{\prime}\right), \bar{\theta}\right]$. This establishes point (ii) of the proposition.

Finally, to observe that there are cases in which principals' expected payoffs lower when the enforcement level increases, suppose $e$ is such that $\theta^{*}(e)$ is smaller than $\bar{\theta}$ but sufficiently close to it. If $e$ increases, stars with ability $\theta>\theta^{*}(e)$ are better off while stars with ability $\theta \leq \theta^{*}(e)$ are either better off or remain the same. Thus, since some types of stars are better off and no type of star is worse off, the principals' expected payoffs across stars' types must decrease. 


\section{References}

[1] Abreu, D. (1988): "On the Theory of Infinitely Repeated Games with Discounting", Econometrica, Vol. 56, pp. 383-396.

[2] Aghion, P. and Bolton, P. (1987): "Contracts as a Barrier to Entry", American Economic Review, Vol. 77, pp. 388-401.

[3] Bernheim, B. and Whinston, M.D. (1990): "Multimarket Contact and Collusive Behavior", RAND Journal of Economics, Vol. 21, pp. 1-26.

[4] Bernheim, B. and Whinston, M.D. (1998): "Exclusive Dealing", Journal of Political Economy, Vol. 106, pp. 64-103.

[5] Compte, O., Jenny, F. and Rey, P. (2002): "Capacity Constraints, Mergers and Collusion", European Economic Review, Vol. 46, pp. 1-29.

[6] De Fraja, G. and Sákovics, J. (2001): "Walras Retrouvé: Decentralized Trading Mechanisms and the Competitive Price", Journal of Political Economy, Vol. 109, pp. 842-863.

[7] De Meza, D. and Selvaggi, M. (2004): "Exclusive Contracts Foster Relationship-Specific Investment", RAND Journal of Economics, Forthcoming.

[8] Edlin, A. and Reichelstein, S. (1993): "Holdups, Standard Breach Remedies, and Optimal Investment", American Economic Review, Vol. 86, pp. 478-501.

[9] Feuerstein, S. (2005): "Collusion in Industrial Economics-A Survey", Journal of Industry, Competition and Trade, Vol. 5, pp. 163-198.

[10] Franco, A. and Mitchell, M. (2005): "Covenants not to Compete, Labor Mobility, and Industry Dynamics", Mimeo, University of Iowa.

[11] Fumagalli, C. and Motta, M. (2005): "Exclusive Dealing and Entry, when Buyers Compete", American Economic Review, Forthcoming.

[12] Green, E. and Porter, R. (1984): "Noncooperative Collusion under Imperfect Price Information", Econometrica, Vol. 52, pp. 87-100.

[13] Lafontaine, F. and Slade, M. (2005): Exclusive Contracts and Vertical Restraints: Empirical Evidence and Public Policy, in Handbook of Antitrust Economics, Paolo Buccirossi (Ed.), Cambridge: MIT Press, Forthcoming. 
[14] Motta, M. Competition Policy: Theory and Practice. Cambridge: Cambridge University Press, 2004.

[15] Rey, P. and Stiglitz, J. (1995): "The Role of Exclusive Territories in Producers' Competition", RAND Journal of Economics, Vol. 26, pp. 431-451.

[16] Rey, P. and Tirole, J. (2005): A Primer on Foreclosure, in Handbook of Industrial Organization, Mark Armstrong and Rob Porter (Eds), Vol. 3, Elsevier, North Holland.

[17] Rotemberg, J. and Saloner, G. (1986): "A Supergame-Theoretic Model of Price Wars during Booms", American Economic Review, Vol. 76 (3), pp. 390-407.

[18] Segal, I. (2003): "Collusion, Exclusion, and Inclusion in Random-Order Bargaining." Review of Economic Studies, Vol. 70 (2), pp. 439-460.

[19] Segal, I. and Whinston, M.D. (2000): "Exclusive Contracts and Protection of Investments", RAND Journal of Economics, Vol. 31 (4), pp. 603-633.

[20] Snyder, C. (1996): "A Dynamic Theory of Countervailing Power", RAND Journal of Economics, Vol. 27 (4), pp. 747-769.

[21] Vasconcelos, L. (2006): "Signalling Through Contractual Commitments", Mimeo, Universidade Nova de Lisboa. 